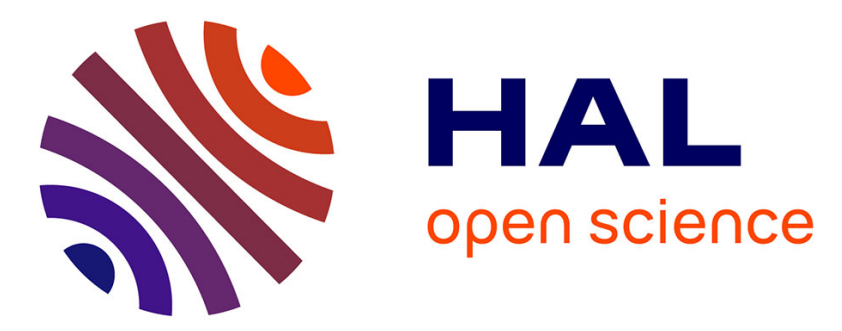

\title{
Inverse modeling of annual atmospheric CO 2 sources and sinks: 1. Method and control inversion
}

\author{
P. Bousquet, P. Ciais, P. Peylin, M. Ramonet, P. Monfray
}

\section{To cite this version:}

P. Bousquet, P. Ciais, P. Peylin, M. Ramonet, P. Monfray. Inverse modeling of annual atmospheric CO 2 sources and sinks: 1. Method and control inversion. Journal of Geophysical Research: Atmospheres, 1999, 104 (D21), pp.26161-26178. 10.1029/1999JD900342 . hal-02923856

\section{HAL Id: hal-02923856 https://hal.science/hal-02923856}

Submitted on 25 Jan 2021

HAL is a multi-disciplinary open access archive for the deposit and dissemination of scientific research documents, whether they are published or not. The documents may come from teaching and research institutions in France or abroad, or from public or private research centers.
L'archive ouverte pluridisciplinaire HAL, est destinée au dépôt et à la diffusion de documents scientifiques de niveau recherche, publiés ou non, émanant des établissements d'enseignement et de recherche français ou étrangers, des laboratoires publics ou privés. 


\title{
Inverse modeling of annual atmospheric $\mathrm{CO}_{2}$ sources and sinks 1. Method and control inversion
}

\author{
P. Bousquet, ${ }^{1}$ P. Ciais, P. Peylin, M. Ramonet, and P. Monfray \\ Laboratorre des Sciences du Climat et de l'Environnement, Gif sur Yvette, France
}

\begin{abstract}
A primary goal of developing the $\mathrm{CO}_{2}$ atmospheric measurement network is to better characterize the sources and sinks of atmospheric $\mathrm{CO}_{2}$. Atmospheric transport models can be used to interpret atmospheric measurements in terms of surface fluxes using inverse methodology. In this paper we present a three-dimensional (3-D) inversion of $\mathrm{CO}_{2}$ measurements in order to infer annual sources and sinks of $\mathrm{CO}_{2}$ at a continental scale (continents and ocean basins) for a climatological year representing the 1985-1995 period. Solving this inverse problem requires (1) a data space representing monthly $\mathrm{CO}_{2}$ measurements, here at 77 sites (surface, ships, planes), (2) a flux space describing a priori fluxes between carbon reservoirs, and (3) a 3-D transport model linking the flux space to the data space. Knowledge of these three elements, together with their associated errors, allows one to reduce the uncertainties of the $\mathrm{CO}_{2}$ sources and sinks. In the 1985-1995 period, for our control inversion, the global continental sink is found to be $2.7 \pm 1.5 \mathrm{Gt} \mathrm{C}_{\mathrm{yr}}{ }^{\mathrm{l}}$ for an optimized deforestation source of $1.4 \pm 0.6 \mathrm{Gt} \mathrm{C} \mathrm{yr}{ }^{1}$, yielding a net land uptake of $1.3 \pm 1.6 \mathrm{Gt} \mathrm{C} \mathrm{yr}^{1}$ (fossil fuel removed). The continental partition of this budget is (in units of Gt $\mathrm{C} \mathrm{yr}^{1}$ ): Arctic $+0.2 \pm 0.3$, North America $-0.5 \pm 0.6$, Europe $-0.3 \pm 0.8$, north Asia $-1.5 \pm 0.7$, tropics (except Asia) $+0.3 \pm 0.9$, tropical Asia $+0.8 \pm 0.4$, and Southern Hemisphere $-0.1 \pm 0.3$. The inferred partition for the controversial Northern Hemisphere $\mathrm{CO}_{2}$ sink reveals that a major sink is located over the north Asia continent. For oceans we find a net global sink of $1.5 \pm 0.5 \mathrm{Gt} \mathrm{C} \mathrm{yr}^{1}$ with the following partition (in units of $\mathrm{Gt} C \mathrm{yr}^{1}$ ): North Pacific $-0.3 \pm 0.2$, North Atlantic $-0.8 \pm 0.3$, equator $+0.6 \pm 0.2$, $20^{\circ} \mathrm{S}-50^{\circ} \mathrm{S}$ oceans $-0.9 \pm 0.3$, and austral ocean $-0.1 \pm 0.1$.
\end{abstract}

\section{Introduction}

$\mathrm{CO}_{2}$ is the second most important greenhouse gas in the Earth's atmosphere, after water vapor. Its concentration has increased by $30 \%$ over the past 200 years in response to industrialization and to land use changes [Intergovernmental Panel on Climate Change (IPCC), 1995]. The industrial source is known with a relatively good level of accuracy [Andres et al., 1993] while the land use induced source is more difficult to estimate [Houghton, 1997]. From the observed $\mathrm{CO}_{2}$ growth rate in the atmosphere, which is documented at many observing sites around the world [Conway et al., 1994], we know that on average, only about half of the human-induced emissions end up being stored in the atmosphere [IPCC, 1995]. The other half is currently reabsorbed by natural resevoirs, oceans, and land biosphere.

If we are to make reliable predictions of future $\mathrm{CO}_{2}$ levels, we need not only to make projections of the human-induced source but also to estimate the response of the oceans and of the land ecosystems to rising $\mathrm{CO}_{2}$. To do so, it is of primary importance to establish a precise diagnostic of today's carbon budget. This requires not only estimation of global $\mathrm{CO}_{2}$ uptake partitioning

\footnotetext{
'Also at Université de Versailles Saint Quentin en Yvelines, Versailles, France

Copyright 1999 by the American Geophysical Union

Paper number 1999JD900342. 0148-0227/99/1999JD900342\$09.00
}

between oceans and continents, but also its space and time distribution. Furthermore, large positive and negative anomalies of the $\mathrm{CO}_{2}$ growth rate, correlated or lag correlated with the climate variability, indicate that we need long time series of observations to remove year-to-year variability from the longterm sources and sinks activity [Conway et al., 1994 ; Keeling et al., 1996a].

Direct atmospheric observations can be used to infer largescale patterns of the $\mathrm{CO}_{2}$ surface fluxes. Small, but accurately measured, gradients in $\mathrm{CO}_{2}$ concentration between different points on the globe relate to the sources distribution and to the atmospheric transport [Keeling et al., 1989; Tans et al., 1990]. In this study we use the monthly mean $\mathrm{CO}_{2}$ measurements made over the past 15 years at 77 sites worldwide with : the Global Atmosphere Watch (GAW) from World Meteorological Organization (WMO), the Climate Monitoring and Diagnostic Laboratory (CMDL) from National Oceanic and Atmospheric Administration (NOAA/USA), the Laboratoire des Sciences du Climat et de l'Environnement (LSCE) from Institut Pierre Simon Laplace (IPSL/France), the CSIRO Division of Atmospheric Reasearch (DAR/Australia), the Atmospheric Environment Service (AES/Canada), and Japan networks. These data are aggregated into the GLOBALVIEW database [Cooperative Atmospheric Data Integration Project: Carbon Dioxide, 1997; Masarie and Tans, 1995] which is a comprehensive database of $\mathrm{CO}_{2}$ concentrations at more than 70 sites, smoothed, interpolated, and extrapolated on a weekly time step over the 1980-1997 period. They are used together with a global model of the atmospheric transport to deduce the $\mathrm{CO}_{2}$ sources and sinks annual magnitude over large areas at the surface of Earth. We use a Bayeasian inverse procedure in order to determine the annual 
magnitude of sources and sinks that gives model $\mathrm{CO}_{2}$ in best agreement with the ent1re data set of atmospheric measurements [Tarantola, 1987; Enting et al., 1993].

We consider several spatial scales in this paper. The spatial scale used for inverse calculation is the regional scale (1000-3000 $\mathrm{km})$. Optimized fluxes are then aggregated at the scale of large ocean basins and continental areas (3000-10 000 km). This spatial scale will be hereinafter referred to as the continental and ocean basins scale. Optimized fluxes are also analyzed for three major latitude bands $\left(15^{\circ} \mathrm{N}-90^{\circ} \mathrm{N}\right.$, tropics, $\left.15^{\circ} \mathrm{S}-90^{\circ} \mathrm{S}\right)$ and at global scale. We optimize annual mean $\mathrm{CO}_{2}$ sources and sinks, but we use montly a priori flux estimates and monthly atmospheric observations. Furthermore, we only consider one climatological year of atmospheric observations, that is, the average of the 1985-1995 period.

Several inverse calculations have been performed since the early 1990 s, mostly relating meridional gradients in $\mathrm{CO}_{2}$ (and isotopes) to the latitudinal distribution of the fluxes [Bousquet et al., 1996; Ciais et al., 1995b; Enting and Mansbridge, 1991]. The inverse method presented here, based on the ideas of Enting et al. [1993] and Tarantola [1987], uses gradients among stations both in latitude and longitude to infer fluxes over different regions of the globe. It has the advantage of estimating the errors on the inferred sources and thus providing some degree of confidence on the results. It has the disadvantage of depending to a certain extent, on some prior knowledge of the problem, such as prior estimates and uncertainties of the sources strength or patterns in their geographical distribution. Thus, we need to verify carefully that the inferred fluxes and their numerical stability are mostly constrained by the atmospheric observations through the atmospheric transport, and not by a priori information.

In the following, we describe the method that is used to infer the $\mathrm{CO}_{2}$ budget (section 2). Also, measurements of $\delta^{13} \mathrm{C}_{1 n} \mathrm{CO}_{2}$ can be used to separate ocean uptake from land uptake within a given band of latitude [Ciais et al., 1995a]. This arises from the fact that ${ }^{13} \mathrm{C}$ fractionations during photosynthetic carbon uptake and air-sea exchange processes are different. However, no $\delta^{13} \mathrm{C}$ data are included in our control inversion. The specific methodology to include $\delta^{13} \mathrm{C}$ data as additional constraints into the inversion is fully described by Bousquet et al. (this issue, the appendix). We then detall the components that are necessary for the inverse procedure: the model of atmospheric transport, the atmopheric data, and the "prior" flux scenario (section 3). We discuss the results for the inferred annual source strengths of our control inversion (hereinafter noted $S_{0}$ ) at global scale in section 4 and at continental and ocean basins scale in section 5 . Special attention is given to the existence of $\mathrm{CO}_{2}$ gradients between marine sites and sites under a more continental influence and to how they relate to the partitioning of the $\mathrm{CO}_{2}$ fluxes between ocean and land.

\section{Method}

\subsection{Cost Function}

Bayesian time-independent inversion is a technique that is used to optimize surface fluxes of atmospheric trace gases against a set of atmospheric data, given a priori knowledge of surface fluxes with standard deviations [Enting et al., 1995, 1993; Hein et al., 1997]. This technique and the statistics related to it are fully described by Tarantola and Vallette [1982], Tarantola [1987], and Enting et al. [1993]. Briefly, we subdivide the surface fluxes into individual sources, each corresponding to a region and/or a specific type of emission (e.g., fossil fuel combustion and photosynthesis). Each individual source has a given spatial pattern, intra-annual variations, and an overall source strength $m_{j}$ (with standard deviation) in gigatons of carbon per year (Gt $\mathrm{C} \mathrm{yr}^{-1}$ ). Annual source strengths $m_{j}$ are the parameters we optimize in order to match the modeled $\mathrm{CO}_{2}$ concentrations with the observed ones. Monthly averaged observations of atmospheric $\mathrm{CO}_{2}$ at 70 monitoring sites were extracted from GLOBALVIEW- $\mathrm{CO}_{2}$ extended database [Cooperative Atmospheric Data Integration Project: Carbon Dioxıde, 1997; Masarie and Tans, 1995] for the period 19851995 , which is our reference period. The seven other sites come from aircraft mesaurements over Japan and Tasmania at different altitudes. All data are used to build a climatological database of $\mathrm{CO}_{2}$ concentrations (represented by a vector $\mathbf{d}_{\text {obs }}$ ). Control inversion $S_{0}$ is thus a steady state experiment performed only with $\mathrm{CO}_{2}$ data. For each regional source we normalize the flux to $1 \mathrm{Gt} \mathrm{C} \mathrm{yr}^{-1}$ (normalized source base function). Then we determine a vector $\mathbf{m}_{\mathbf{p}}$ containing a priori knowledge of annual source strengths for all sources and all regions (see section 3 ).

Source base functions are prescribed to an atmospheric transport model (named $g$ ) which produces the normalized model responses at all monitoring sites for each regional flux component $\mathbf{d}=g(\mathbf{m})$. This step is called the direct problem. The inverse problem, that is, deducing optimized sources and sinks from atmospheric measurements, is overconstrained as the dimension of $\mathbf{d}$ is greater than the dimension of $\mathbf{m}$. For the standard inversion, we use a vector $\mathbf{d}$ of $77 \times 12=924$ elements and a vector $\mathbf{m}$ of 46 individual sources to describe $\mathrm{CO}_{2}$ fluxes. Finally, the error due to the atmospheric transport model is not considered mathematically in this paper but will be considered as part of the sensivity study [Bousquet et al., this issue].

Assuming that all uncertainties are Gaussian and uncorrelated spatially and temporally, solving the inverse problem to infer optimized sources and sinks means to minimize the cost function $S(\mathbf{m})$ given by Tarantola [1987]:

$$
\begin{aligned}
S(\mathbf{m})= & \frac{1}{2}\left\{\left[g(\mathbf{m})-\mathbf{d}_{\mathrm{obs}}\right]^{t} \mathbf{C}_{d}^{-1}\left[g(\mathbf{m})-\mathbf{d}_{\mathrm{obs}}\right]\right. \\
& \left.+\left(\mathbf{m}-\mathbf{m}_{p}\right)^{t} \mathbf{C}_{m}^{-1}\left(\mathbf{m}-\mathbf{m}_{p}\right)\right\}
\end{aligned}
$$

here $\mathbf{C}_{d}$ is the diagonal covariance matrix for atmospheric data and $\mathbf{C}_{m}$ is the diagonal covariance matrix for a priori fluxes. The expression of $g(\mathbf{m})$ depends on the tracer studied and on the model used.

\subsection{Solution of the Inverse Problem}

Atmospheric transport of an inert tracer like $\mathrm{CO}_{2}$ is a linear operator. It means that $\mathrm{CO}_{2}$ concentration at a given point of the atmosphere $\left(\chi_{\mathrm{CO}_{2}}\right)$ can be expressed as a linear combination of the modeled responses, $\hat{\chi}_{1}$, of the normalized source base functions, $F_{\text {, }}$, as

$$
\chi_{\mathrm{CO}_{2}}=\sum_{J=1}^{N_{s}} m_{J} \bar{\chi}_{J} \quad \text { with } \quad \frac{d\left(\rho \hat{\chi}_{J}\right)}{d t}=\hat{F}_{J}
$$

where $N_{s}$ is the number of source base functions, $m$, represents the annual source strength of the $j$ th source. In a matrix form we can write vector $\mathbf{d}$ of model outputs as

$$
\mathbf{d}=\mathbf{G} \mathbf{m}
$$

where $G_{y}$ is the contribution of source $j$ to the concentration at site $i$ for a given month. Matrix $\mathbf{G}$ has one more column 
corresponding to a global $\mathrm{CO}_{2}$ "offset" which is optimized at the same time as the source strengths. This global "offset" represents the average $\mathrm{CO}_{2}$ concentration in the atmosphere in the absence of any sources and sinks. $G$ has additional rows which insure global mass conservation and allow specific constraints on a group of individual sources (see section 3 ).

$$
\begin{aligned}
S(\mathbf{m})= & \frac{1}{2}\left[\left(\mathbf{G} \mathbf{m}-\mathbf{d}_{\mathrm{obs}}\right)^{t} \mathbf{C}_{d}^{-1}\left(\mathbf{G} \mathbf{m}-\mathbf{d}_{\mathrm{obs}}\right)\right. \\
& \left.+\left(\mathbf{m}-\mathbf{m}_{p}\right)^{t} \mathbf{C}_{m}^{-1}\left(\mathbf{m}-\mathbf{m}_{p}\right)\right]
\end{aligned}
$$

From Tarantola [1987] we obtain the maximum likelihood vector $\mathbf{m}$ which corresponds to the optimized annual sources and sinks as

$$
\langle\mathbf{m}\rangle=\mathbf{m}_{p}+\left(\mathbf{G}^{t} \mathbf{C}_{d}^{-1} \mathbf{G}+\mathbf{C}_{m}^{-1}\right)^{-1} \mathbf{G}^{t} \mathbf{C}_{d}^{-1}\left(\mathbf{d}_{\mathrm{obs}}-\mathbf{G} \mathbf{m}_{p}\right)
$$

and the a posteriori covariance matrixes $\mathbf{C}_{m}{ }_{m}$ and $\mathbf{C}_{d}{ }_{d}$ for fluxes and atmospheric data, respectively:

$$
\begin{aligned}
& \mathbf{C}_{m}^{\prime}=\left(\mathbf{G}^{\prime} \mathbf{C}_{d}^{-1} \mathbf{G}+\mathbf{C}_{m}^{-1}\right)^{-1} \\
& \mathbf{C}_{d}^{\prime}=\mathbf{G C}_{m}^{\prime} \mathbf{G}^{\prime}
\end{aligned}
$$

The matrix $\left(\mathbf{G}^{t} \mathbf{C}_{d}^{-1} \mathbf{G}+\mathbf{C}_{m}^{-1}\right)^{-1}$ is inverted using either singular value decomposition (SVD) or Choleski decomposition techniques (Interactive Data Language (IDL) numerical package, adapted from Press, et al. [1987]).

\section{Required Components of the Inversion}

As we have seen in section 2 , continental synthesis inversion requires three sets of information: a set of atmospheric observations to be fitted, a set of source base functions, and a set of calculated model responses, the latter being computed from a global model of atmospheric transport.

\subsection{Atmospheric Data}

We use a subset of the GLOBALVIEW- $\mathrm{CO}_{2}$ database [Cooperative Atmospheric Data Integration Project: Carbon Dioxide, 1997; Masarie and Tans, 1995], plus vertical profiles at a few selected locations. GLOBALVIEW- $-\mathrm{CO}_{2}$ is a data set of $\mathrm{CO}_{2}$ concentrations where the time series of individual discrete flasks or continuous record is smoothed in the time domain. Gaps in the data are filled using an extension scheme as described by Masarie and Tans [1995] and Thoning et al. [1989]. Thus GLOBALVIEW- $\mathrm{CO}_{2}$ provides smoothed continuous $\mathrm{CO}_{2}$ records on a weekly time step at more than 80 monitoring sites between 1980 and 1995. As many new measurement sites appeared between 1980 and 1985 , we discard data for this period to focus on the 1985-1995 period, which is our reference period in this paper. This choice is to limit the influence of changes in the number of sites of the network on the solution of the inversion.

It is important to note that GLOBALVIEW- $\mathrm{CO}_{2}$ employs data from different networks, although NOAA CMDL data are by far the most extensive. Thus possible calibration offsets or errors between networks may translate into $\mathrm{CO}_{2}$ differences between stations. Nevertheless, the data included in GLOBALVIEW- $\mathrm{CO}_{2}$ are part of the WMO GAW program, and numerous intercomparisons between the different groups have shown that the $\mathrm{CO}_{2}$ offsets among the main contributing networks do not exceed 0.5 ppmv.

Two time series of aircraft measurements are also used in addition to the GLOBALVIEW- $\mathrm{CO}_{2}$ data. Above Sendai (Japan, $140^{\circ} \mathrm{E}, 38^{\circ} \mathrm{N}$ ), data from 1982 to 1994 are grouped into altitude bands: 0-2 km, 2-4 km, 4-8 km, and $8 \mathrm{~km}$-tropopause [Tanaka et al., 1987]. Above Cape Grim (Tasmania, $140^{\circ} \mathrm{E}, 40^{\circ} \mathrm{S}$ ), we have grouped the 1974-1991 measurements in two levels: $3 \mathrm{~km}$ and $6 \mathrm{~km}$ [Pearman and Beardsmore, 1984; Monfray et al., 1996; Pak et al., 1997]. Aircraft measurements are smoothed within the time domain using exactly the same procedure as for surface data [Thoning et al., 1989]. However, aircraft data are not extrapolated beyond the measured time domain.

The map of all measurement sites is plotted on Figure 1: most of the sites are located in the Northem Hemisphere (57 of 77), and most stations are located in the marine boundary layer. For each site we calculate 12 monthly values that are averages representing the $1985-1995$ period. We also compute 12 monthly standard deviations for all sites. The procedure to calculate these monthly averages is detailed in Appendix A.

\subsection{A Priori Flux Scenario}

3.2.1. Fluxes. For each type of source involved in the $\mathrm{CO}_{2}$ budget we establish a global map of a priori fluxes on a monthly basis. The sources which are considered in this paper are listed and briefly summarized in Table 1 . They correspond to fossil fuel emissions (FOS), land use changes (DEF), gross primary production over lands (GPP), total respiration over lands (RES), land net uptake (BIO_UPT), and net ocean fluxes (OCE).

Each source is further subdivided into several components corresponding to different regions (source regions) which determines the source base functions. Note that for land areas the number of source base functions is 3 times the number of source regions because we have three spatial and temporal patterns representing the continental exchanges (GPP, RES, and BIO_UPT). We choose $3 \times 11$ regions to account for continental fluxes, eight regions to account for ocean fluxes (see Figure 2). Moreover, three tropical regions are used for land use changes (tropical America, tropical Africa, and tropical Asia), and one global region is used for fossil fuel emissions. These geographical patterns determine 37 source base functions for continental processes and eight source base functions for oceanic ones. For further details on the a priori scenario, please refer to Appendix B. One should notice that for land uptake (BIO_UPT) we use the spatial pattern from Friedlingstein et al. [1995]. However, we set the a priori value of BIO_UPT to $0.0 \mathrm{Gt} \mathrm{C} \mathrm{yr}^{1}$ for each region with large standard deviations of $1.5 \mathrm{Gt} \mathrm{C} \mathrm{yr}^{1}$ for nontropical regions and $0.5 \mathrm{Gt} \mathrm{C} \mathrm{yr}^{1}$ for tropical regions.

3.2.2. Errors. For each source base function a standard deviation associated to the annual flux is determined either as a percentage of the flux (gross fluxes) or as an arbitrary large value. For gross fluxes (GPP and RES) we set the a priori standard deviation $\sigma_{j}$ proportional the flux itself $(20 \%)$. Then we compute the error $\sigma_{j, k}$ associated to each region $k$ according to the assumption of uncorrelated regions (nb_comp is the number of source base component of type $j$ ).

$$
\sigma_{j}^{2}=\sum_{k=1}^{\text {nb_comp }} \sigma_{j, k}^{2}
$$

For atmospheric growth rate, fossil fuel emissions and land use change we take the IPCC [1995] estimates of $\sigma_{J}$ (Table 1). For ocean and land uptake, which are the most uncertain net fluxes, 


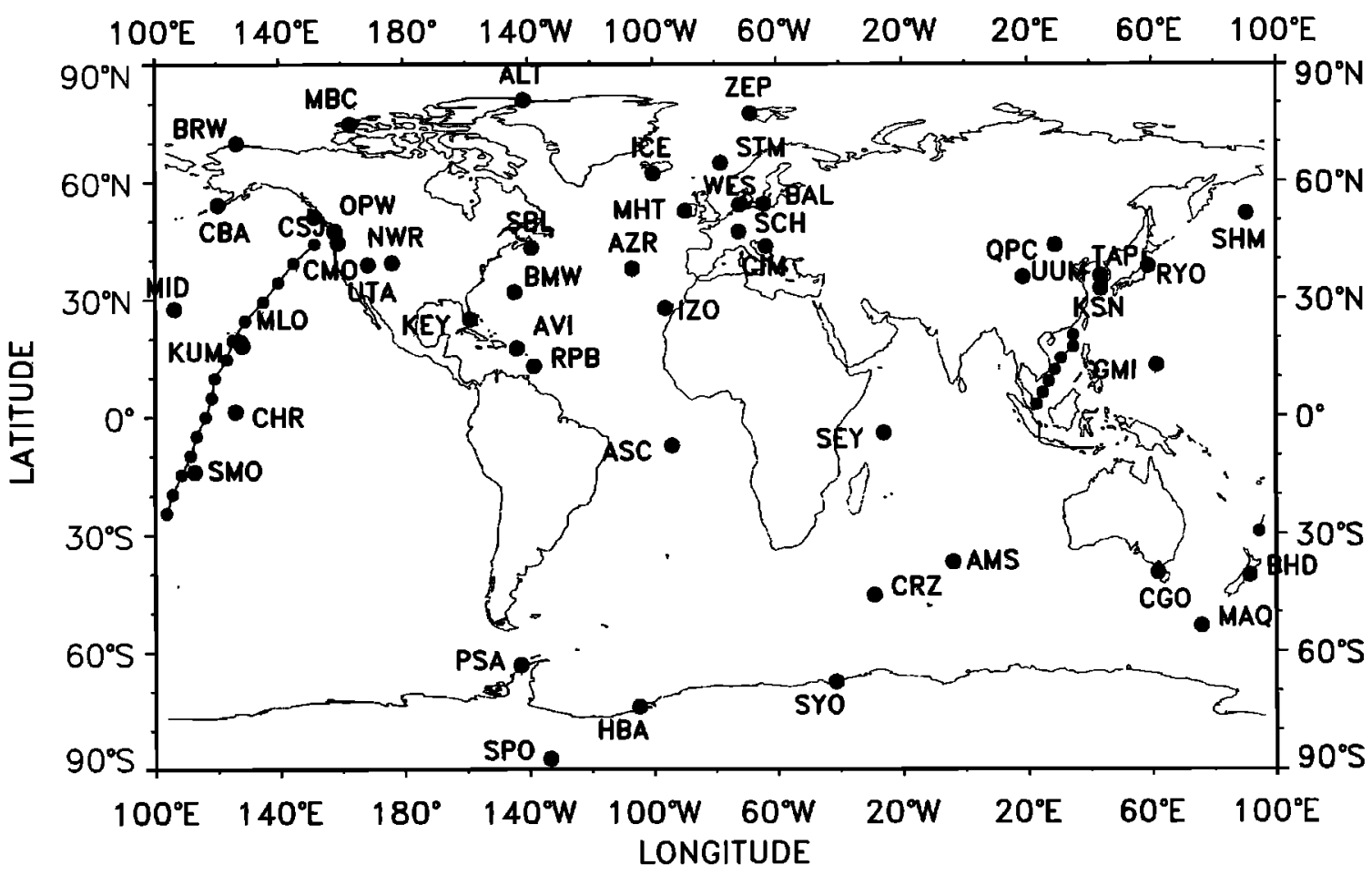

Figure 1. Atmospheric network used for the inverse calculation $S_{0}$. Dots represent ground measurements made by different research groups around the world. Lines represent ship data. Small planes indicates vertical profiles used in the inversion. ALT, Alert; MBC, Mould Bay; ZEP, Spitzberg; BRW, Barrow Point; STM, Station M; ICE, Iceland; CBA, Cold Bay; WES, Westerland; MHT, Mace Head; SHM, Shemya Island; CSJ, Cape St James; OPW, Olympic Peninsula; SCH, Schauinsland; CMO, Cape Meares; CIM, Monte Cimone; SBL, Sable Island; NWR, Niwot Ridge; UTA, Utah; RYO, Ryori; AZR, Terceira Island; TAP, Tae-ahn Peninsula; QPC, Qinghai Province; KSN, Korean station; BMW, Bermuda West; IZO, Tenerife; MID, Sand Island; KEY, Key Biscayne; KUM, Cape Kumukahi; MLO, Mauna Loa; AVI, S $^{t}$ Croix; GMI, Guam Island; RPB, Ragged Point; CHR, Christmas Island; SEY, Seychelles; ASC, Ascension Island; SMO, American Samoa; AMS, Amsterdan Island; CGO, Cape Grim; BHD, Baring Head; CRZ, Crozet Island; MAQ, Maquarie; PSA, Palmer Station; MAW, Mawson; SYO, Syowa; HBA, Halley Bay; SPO, South Pole; P01 to P16, Pacific cruises; C01 to C07, China Sea cruises; S02 to S06, Aircraft measurements above Japan; CG4 and CG6, Aircraft measurements above Tasmania.

we assign arbitrary large regional errors so that global errors are of $\pm 3.0 \mathrm{Gt} \mathrm{C} \mathrm{yr}^{1}$ and $\pm 3.6 \mathrm{Gt} \mathrm{C} \mathrm{yr}^{1}$ respectively . Large errors limit the bias introduced by the use of a priori flux values on the result of the inversion.

\subsection{Atmospheric Transport}

The calculations of the modeled concentrations produced by source base functions are performed with the TM2 model
[Heimann, 1995] using 9 sigma vertical levels at a $7.5^{\circ} \times 7.5^{\circ}$ horizontal resolution [Ramonet, 1994]. Analyzed meteorological data for the year 1990 [European Center for Medium-Range Weather Forecast (ECMWF), 1994] are used both for horizontal and vertical transport (convection and vertical diffusion). The time step of the meteorological fields is 12 hours, whereas the model time step is 3 hours. Advection is calculated using the Russel and Lerner [1981] slope scheme. In each grid box and at

Table 1. Global Processes, Annual Fluxes and Errors Involved in Atmospheric $\mathrm{CO}_{2}$ Cycle

\begin{tabular}{|c|c|c|c|}
\hline Process & Flux and Errors & Seasonality & References \\
\hline Atmospheric increase & $3.1 \pm 0.1$ & - & Conway et al [1994] \\
\hline Anthropic perturbation & $7.5 \pm 1.1$ & - & IPCC $[1995]$ \\
\hline Fossil fuels & $5.9 \pm 0.3$ & yes & $\begin{array}{l}\text { Andres et al [1997] } \\
\text { Rotty [1987] }\end{array}$ \\
\hline Deforestation & $1.6 \pm 1.0$ & yes & Houghton [1997] \\
\hline Biotic fluxes & $-1.8 \pm 1.6$ & - & IPCC,$[1995]$ \\
\hline GPP & $-100 \pm 20$ & yes & $\begin{array}{l}\text { Denning et al. [1996], } \\
\text { Sellers et al. [1996a,b, 1986] }\end{array}$ \\
\hline Total respiration & $100 \pm 20$ & yes & Denning et al. [1996] \\
\hline biotıc uptake & $-1.8 \pm 1.6$ & yes & Frtedlingstein et al. [1995] \\
\hline Oceanic fluxes & $-2.0 \pm 0.8$ & - & $I P C C[1995]$ \\
\hline oceanic uptake plus seaonality & $-1.2 \pm 0.8$ & yes & Takahashi et al. [1997] \\
\hline
\end{tabular}

Fluxes and Errors are Expressed in $\mathrm{Gt} \mathrm{yr}^{-1}$. 


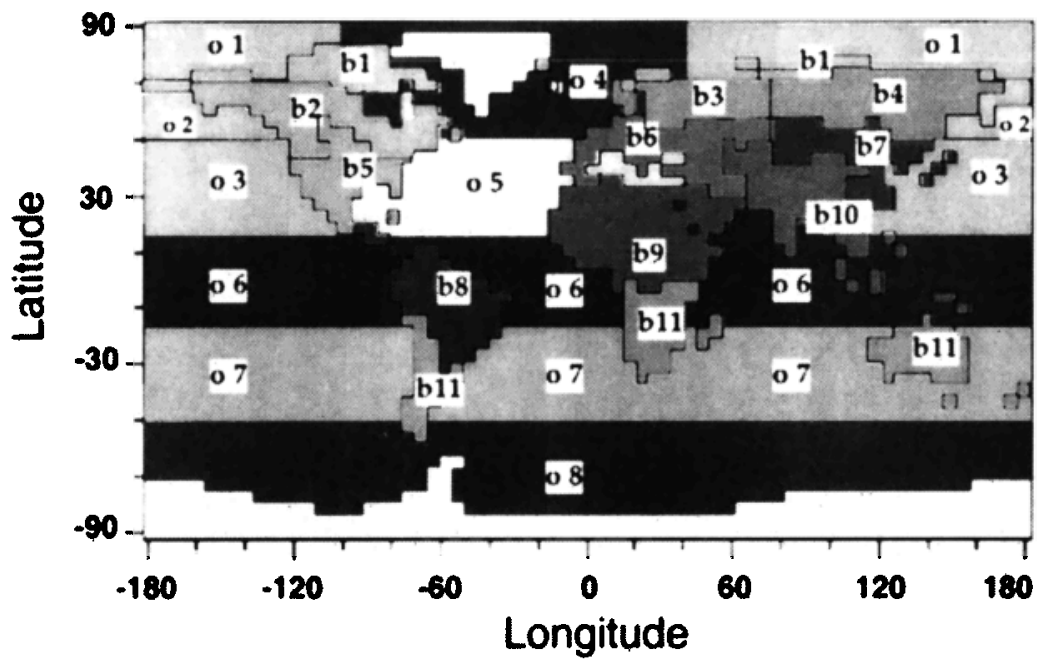

Figure 2. Oceanic (o 1 to $\circ$ 8) and continental (bl to b1 1) regions used by the control inversion $S_{0}$ : bl, Arctic (north of $65^{\circ} \mathrm{N}$ ); b2, Boreal North America; b3, Boreal Europe; b4, Boreal Asia; b5, Temperate North America; b6, Temperate Europe; b7, temperate Asia; b8, tropical South America; b9, tropical Africa; b10, tropical Asia; b11, southern nontropical hemisphere; and o 1, north of $65^{\circ} \mathrm{N}$; o 2, North Pacific; o 3, far North Atlantic; o 4, North Atlantic; o 5, equatorial oceans, o 6, subantarctic and subtropical oceans; o 7, austral ocean (south of $50^{\circ} \mathrm{S}$ ).

each time step this scheme calculates the concentrations as well as the gradient of concentration in the three physical directions (longitude/latitude/altitude). Turbulent vertical transport is calculated by stability-dependent vertical diffusion using the parametrisation of Louis [1979]. Convection is represented using Tiedtke's [1989] scheme, which is based on humidity convergence in the low atmosphere. As explained by Heimann [1995], there is no explicit horizontal diffusion in this version of the model.

The TM2 model is part of the range of models in the TRANSCOM intercomparison experiment (Special project of the IGBP Global Analysis, Interpretation, and Modelling (GAIM) Task Force, http://gaim.sr.unh.edu/Projects/TRANSCOM/) that do not present a strong "rectifier" effect of concentrations above continents [Law et al., 1996; Denning et al., 1997a]. It has the advantage of fast computational performances which allows the use of many source base functions. The TRANSCOM I experiment revealed that some models could produce large positive $\mathrm{CO}_{2}$ zonal mean profiles (south to north) when prescribed with a purely seasonal biotic source (no annual net flux). Such an effect is caused by both the accumulation of respired $\mathrm{CO}_{2}$ during winter over Northern Hemisphere continents and the dilution of the uptake imposed by photosynthesis during summer. This so called "rectifier" effect of concentrations is documented by Denning et al. [1995]. It ịntroduces large uncertainties associated to vertical transport especially over continents [Denning et al., 1997a]. The exact intensity of this effect still remains to be quantified. For instance, recent tests have shown that the Colorado State University (CSU) model probably greatly overestimates this effect [Denning et al., 1997b]. The TM2 model does not produce a significant rectifier effect above continents due to its coarse vertical resolution near the surface $(0.4,1.2$, and $3.6 \mathrm{~km}$ for the center of the three lowest grid boxes, respectively). At the opposite, the TM3 model introduces a rectifier effect of almost 2 ppmv in the biospheric TRANSCOM I experiment [Law et al., 1996]. The TM3 model is a new version of TM2 model with a $4^{\circ} \times 5^{\circ}$ horizontal resolution and 19 vertical levels. It was developed by M. Heimann at Max
Planck Institute. Using both TM2 and TM3, Bousquet et al. (this issue, section 4) analyze the influence of atmospheric transport on the results of the inversion.

Each source base function consists of 12 monthly flux fields (with spatial patterns). Each base function has been run for 4 years in the atmospheric transport model to achieve steady state [Heimann et al., 1989]. Only 1 year of atmospheric forcing has been used repeatedly during the 4 years of simulation (ECMWF, year 1990). The last year of simulation is used to calculate monthly modeled $\mathrm{CO}_{2}$ concentrations at each site. Instead of taking the average $\mathrm{CO}_{2}$ concentration in the grid box, we have sampled the model outputs of the fourth year of simulation at the exact position of the monitoring sites. The concentration at the location of the monitoring sites is taken precisely using the concentrations slopes given by the advection scheme. Moreover, in order to account (partly) for data selection we have extracted the concentrations of the closest oceanic model box for two coastal monitoring sites, Bermuda (BMW) and Cape Grim (CGO). No other model autput selection has been performed.

\subsection{Additional Constraints}

Additional independent constraints are introduced as additional rows to the $G$ matrix. These constraints are of three kinds. First, we use the global trends which are determined with excellent precision from atmospheric network, $1.4 \pm 0.1 \mathrm{Gt} \mathrm{C} \mathrm{yr}{ }^{1}$ for $\mathrm{CO}_{2}$, with a small error bar to force the global $\mathrm{CO}_{2}$ budget. Second, we impose the sum of GPP and RES over each continental region to be equal to zero because we consider an explicit biospheric uptake (BIO_UPT) to close the $\mathrm{CO}_{2}$ budget over land areas. Third, we constrain the global annual net land

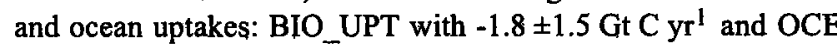
with $-2.0 \pm 0.8 \mathrm{Gt} \mathrm{C} \mathrm{yr}^{-}$. These constraints correspond to independent information that we can use to improve global constraints on fluxes [IPCC, 1995]. Variances associated with these constraints are smaller than the sum of regional variances as defined above. 


\section{Optimized Global and Hemispheric Net Fluxes}

\subsection{Modeled $\mathrm{CO}_{2}$ Concentrations}

The optimized time series at eight monitoring sites are shown on Figure 3 together with the a priori time series and observations. The fit of monthly means is improved by the inverse procedure and is satisfying for most sites. However, the inversion performs better for nontropical sites. There are only a few sites where the fit to $\mathrm{CO}_{2}$ signal is poorly reproduced (BAL, SHM, CIM, TAP, C07, UUM, P11) either in seasonal cycle or annual mean. On Figure 3 station C07 (China Sea boat) shows the worse fit to the observations that we obtain. Atmospheric tracer transport is difficult to reproduce in the tropics because a large part of the tracer is injected higher in altitude by convective mixing and vertical diffusion depending on the position of the Intertropical Convergence Zone (ITCZ). Especially, part of the $\mathrm{CO}_{2}$ emitted over the Northern Hemisphere and traveling south is brought aloft at the ITCZ and diluted higher up. The vertical processes involved depend greatly on the parametrization used [Law et al., 1996; Mahowald et al., 1995]. Also we know that some continental sites where $\mathrm{CO}_{2}$ concentrations can depend strongly on local effects are not well represented (some months) by the coarse resolution of the transport model used (e.g., BAL or TAP). Thus, even if the fit is correct, there is a risk that our
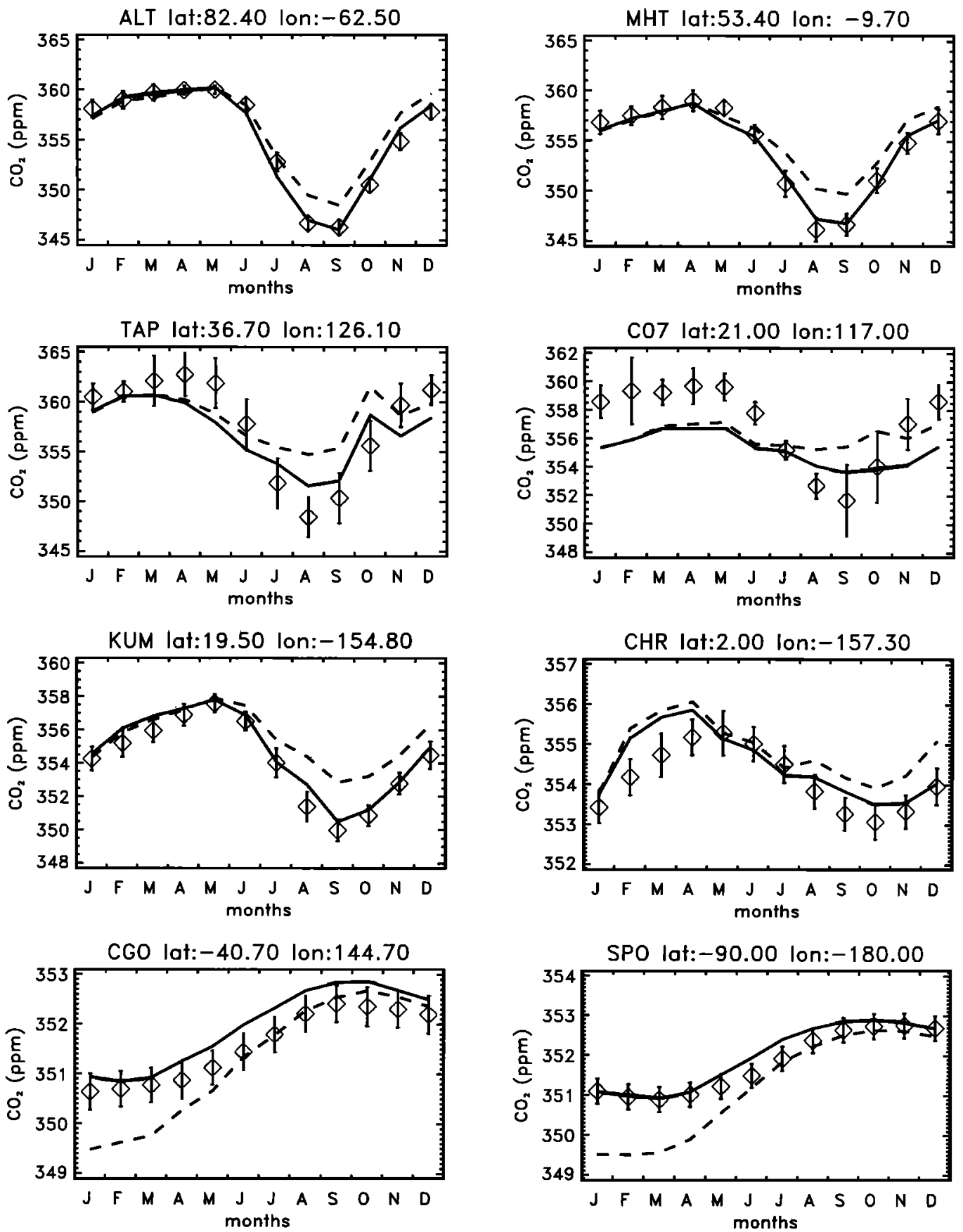

Figure 3. Modeled and observed $\mathrm{CO}_{2}$ concentrations for 8 of the 77 monitoring sites used in control inversion $S_{0}$. Dots stand for atmospheric data (one climatological year of observations averaging the 1985-1995 period). Dashed line is for the a priori modeled concentrations. Solid line is for the optimized model concentrations. 


\section{Latitude Gradient}

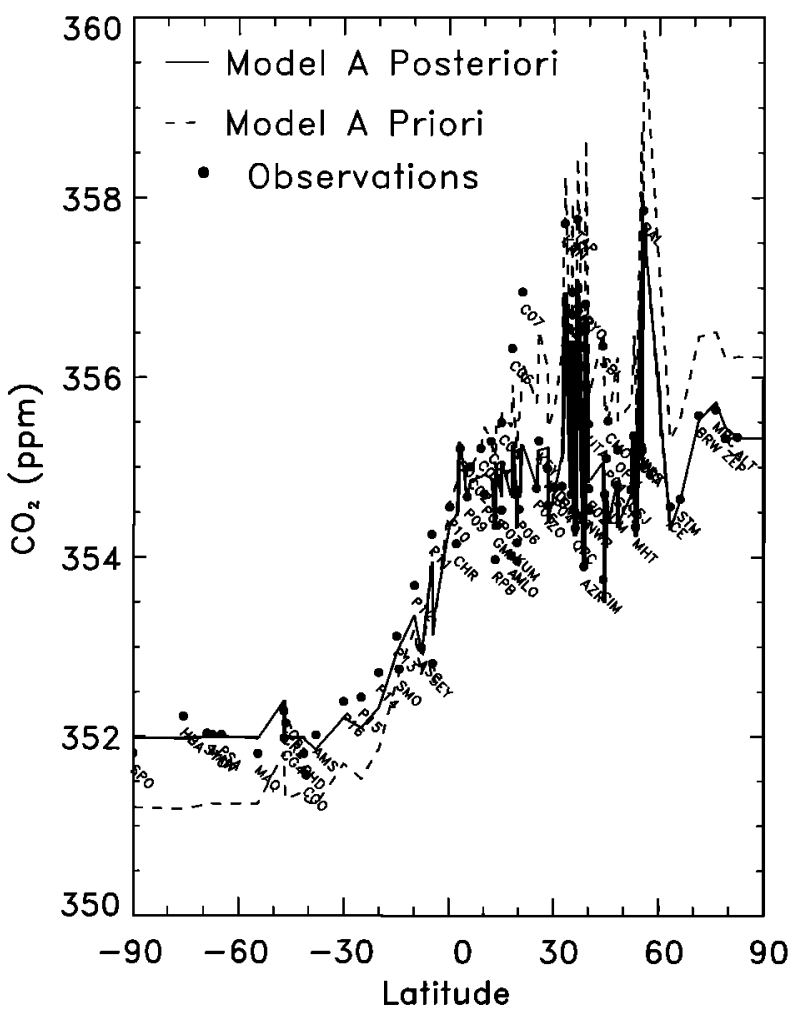

Figure 4. North-to-south gradient. Modeled and observed $\mathrm{CO}_{2}$ annual concentrations for the 77 monitoring sites used in the control inversion $S_{0}$. Dots stand for atmospheric data (one climatological year of observations averaging the 1985-1995 period. Dashed line is for the a priori modeled concentrations. Solid line is for the optimized model concentrations. inverse method converts model bias in term of changes in the flux estimates.

Figure 4 presents north to south annual concentrations at monitoring sites. The inversion reduces zonal north-to-south annual gradient and matches rather well annual concentrations at most of the sites. One can notice a systematic offset of the concentrations at $\mathrm{CGO}$ station that will be discussed in section 5.1. Figure 5 plots the longitudinal gradient of concentration for sea level stations located within $35^{\circ} \mathrm{N}-65^{\circ} \mathrm{N}$ latitude band. This represents 24 stations: seven in North Pacific Ocean, five in north America, five in North Atlantic Ocean, three in Europe, and four in Asia. One should note that large $\mathrm{CO}_{2}$ gradients between continental and marine sites are globally reproduced by the source adjustment in this latitude band. The two deeps of the Pacific and Atlantic Oceans are very well matched. The inverse procedure reproduces the high level of $\mathrm{CO}_{2}$ concentrations found over continents (KSN and TAP) except for the Baltic Sea site (BAL). On the west part of the North Atlantic, optimized concentration is averaged between Bermuda island (BMW) and Sable island (SBL) and does not completely reach the high $\mathrm{CO}_{2}$ level observed at SBL. The two sites of Monte Cimone (CIM) and Niwot Ridge (NWR) are not completely resolved by the inverse procedure. This result can be explained by the location of these sites at $2165 \mathrm{~m}$ and $3475 \mathrm{~m}$ respectively above sea level. For such sites at high altitude the coarse resolution of the model on the vertical direction makes it difficult to represent them properly.

\subsection{Global and Latitudinal Totals}

Net $\mathrm{CO}_{2}$ fluxes inferred by control inversion $S_{0}$ at the global scale and at the hemispheric scale for three latitudinal bands are given in Table 2. Please note that (1) fossil fuel emissions have been removed from all continental fluxes presented in the following and (2) some $\pm 0.1 \mathrm{Gt} \mathrm{C} \mathrm{yr}^{-1}$ discrepancies occur in our

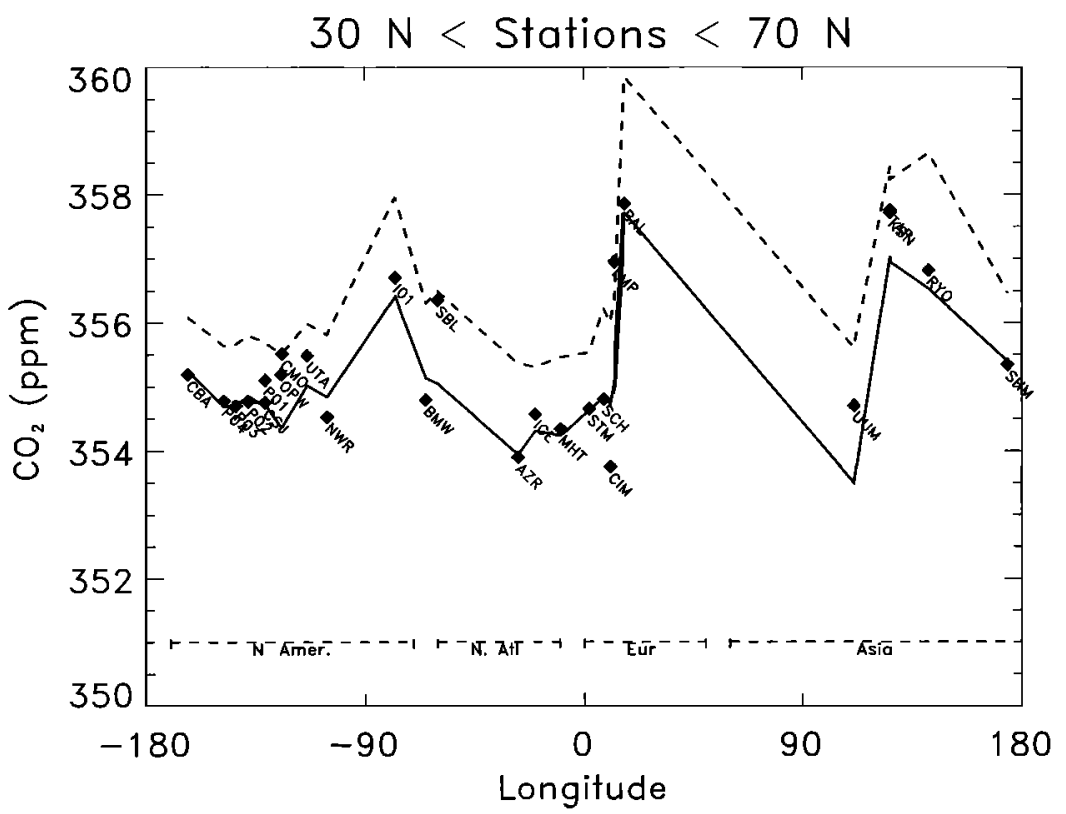

Figure 5. West-to-east gradient. Modeled and observed $\mathrm{CO}_{2}$ annual concentrations for monitoring sites located between $30^{\circ} \mathrm{N}$ and $70^{\circ} \mathrm{N}$. Dots stand for annual means of atmospheric data (one climatological year of observations averaging the 1985-1995 period. Dashed line is for the a priori modeled concentrations. Solid line is for the optimized model concentrations. 
Table 2. Global Results of the Standard Inversion $S_{0}$

\begin{tabular}{lccccc}
\hline & Fossils & Land use & $\begin{array}{c}\text { Ocean } \\
\text { Uptake }\end{array}$ & $\begin{array}{c}\text { Land } \\
\text { Uptake }\end{array}$ & Total \\
\hline $20-90^{\circ} \mathrm{N}$ & 5.3 & 0.0 & -1.1 & -2.1 & 2.1 \\
Tropics & 0.3 & 1.3 & 0.6 & -0.4 & 1.9 \\
$20-90^{\circ} \mathrm{S}$ & 02 & 0.0 & -1.0 & -0.1 & -0.9 \\
& & & & & \\
A posteriori total & 5.9 & 1.3 & -1.5 & -2.7 & 3.1 \\
A priori total & 59 & 1.3 & -1.2 & 0.0 & 6.3 \\
\hline
\end{tabular}

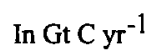

tables due to round off errors. At a global scale we obtain a global biospheric sink of $2.7 \pm 1.5 \mathrm{Gt} \mathrm{C} \mathrm{yr}^{-1}\left(1.4 \mathrm{Gt} \mathrm{C} \mathrm{yr}^{-1}\right.$ for total land uptake with deforestation added) and an ocean sink of $1.5 \pm 0.5 \mathrm{Gt} \mathrm{C} \mathrm{yr}^{-1}$ for the $1985-1995$ period. Note that the global calculated flux partition between oceans and continents remains within error bars of the IPCC budget (the biospheric sink is higher than IPCC by $0.9 \mathrm{Gt} \mathrm{C} \mathrm{yr}^{-1}$ and the ocean sink is smaller by $0.5 \mathrm{Gt} \mathrm{C} \mathrm{yr}^{-1}$ ). One should note, however, that the IPCC budget is set for the 1980-1989 period and not for 1985-1995 decade as in this work. The rather small ocean sink is consistent with the range of $1.5-2.2 \mathrm{Gt} \mathrm{C} \mathrm{yr}^{-1}$ of the recent ocean model intercomparisons conduced in the ocean Carbon-Cycle model Intercomparison Project (OCMIP, IGBP/GAIM project, http://www.ipsl.jussieu.fr/OCMIP/, Orr et al., [1996]).

We find that $80 \%$ of the biospheric sink is located at the mid

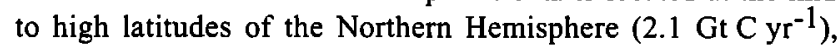
against $15 \%$ in the tropics and only $5 \%$ in the Southern Hemisphere. Considering the net biospheric flux (BIO_UPT+DEF), we find that the tropical biosphere is a net source of $1.0 \mathrm{Gt} \mathrm{C} \mathrm{yr}{ }^{-1}$. The ocean sink is equally partitioned between the Northern Hemisphere $\left(-1.1 \mathrm{Gt} \mathrm{C} \mathrm{yr}^{-1}\right)$ and the Southern Hemisphere $\left(-1.0 \mathrm{Gt} \mathrm{C} \mathrm{yr}{ }^{-1}\right)$, with an equatorial source

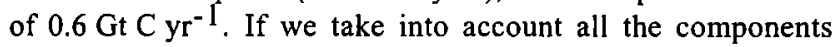
(including fossil fuels), one can see that mid and high latitudes of the Northern Hemisphere are a net source of $2.1 \mathrm{Gt} \mathrm{C} \mathrm{yr}^{-1}$, and tropics are a net source of $1.7 \mathrm{Gt} \mathrm{C} \mathrm{yr}^{-1}$, whereas the Southern Hemisphere has a net sink of $0.9 \mathrm{Gt} \mathrm{C} \mathrm{yr}^{-1}$. In the following, fossil fuel emissions are always removed from land flux values.

Concerning the reduction of a posteriori flux uncertainties, Table 3 shows that ocean flux uncertainties are globally more reduced than continental flux uncertanties (see last column of Table 3). This result can be explained by the fact that we use only eight source base functions to represent the ocean in the inversion and also because the atmospheric network contains mainly measurement sites representative of the marine boundary layer which therefore constrain better the fluxes over oceanic regions.

\subsection{Comparison With Other Studies}

Previous studies have estimated the $\mathrm{CO}_{2}$ surface fluxes for the 1980s and the 1990s [Bousquet et al., 1996; Clais et al., 1995b; Enting and Mansbridge, 1991; Enting et al., 1995; Keeling et al., 1989; Rayner et al., 1997; Tans et al., 1990]. These studies cover different time periods and use mainly three types of constraints to infer net fluxes. Table 4 presents their results as well as constraints and covered periods. First, Keeling et al. [1989] take historical $\mathrm{CO}_{2}$ and $\delta^{13} \mathrm{C}$ atmospheric data to constrain a box model based on the work by Oeschger et al. [1975]. Second,
Tans et al. [1990] have used two different constraints: North-tosouth zonal mean $\mathrm{CO}_{2}$ gradient is the primary constraint and airsea $\triangle p \mathrm{CO}_{2}$ data are the secondary constraint. Third, with the development of three-dimensional transport models at the beginning of the $1990 \mathrm{~s}$, concentration differences between monitoring sites have been widely used by several authors to constrain $\mathrm{CO}_{2}$ fluxes [Enting et al., 1995; Kaminski et al., 1997; Rayner et al., 1997]

All these works cover different periods of time. For the 1980s, differences between the scenarios of Keeling et al. [1989] and Tans et al. [1990] have been already analyzed [Tans et al., 1995]. Primary constraints are not the same, but above all, $\Delta p \mathrm{CO}_{2}$ data used by Tans et al. [1990] are not compatible with a strong ocean uptake. For 1992-1993, Ciais et al. [1995b] find a strong sink in the continental biosphere of the mid-Northern Hemisphere latitudes, using both $\mathrm{CO}_{2}$ and $\delta^{13} \mathrm{C}$ atmospheric data in a double deconvolution. A complementary study presented by Bousquet et al. [1996] reproduced part of Ciais et al. work but with the 3-D transport model TM2 [Heimann et al., 1989]. Differences in atmospheric transport between the 2-D model and the 3-D model contribute to both a $0.5 \mathrm{Gt} \mathrm{C} \mathrm{yr}^{-1}$ reduction of the equatorial source and of the global mid-latitude sink (ocean plus continents). However, the main sources and sinks regions inferred by Ciais et al. for early 1990s are confirmed by the work of Bousquet et al. 1996].

On average for the 1980s and the 1990s, the work of Rayner et al. [1997], based on the work of Enting et al. [1995], is the most comparable work to our control inversion $S_{0}$. The main differences between the two approaches are the transport model

Table 3. Regional Results of the Standard Inversion $S_{0}$

\begin{tabular}{lrrr}
\hline & A Posteriori & A Priori & Error \\
\hline Continents & $-1,3 \pm 1,6$ & $1.6^{*} \pm 4,0$ & 60 \\
$20^{\circ} \mathrm{N}-90^{\circ} \mathrm{N}$ & $-2,2 \pm 1,2$ & $0,0 \pm 3,7$ & 68 \\
Arctic & $0,2 \pm 0,3$ & $0,0 \pm 0,5$ & 50 \\
North America & $-0,5 \pm 0,6$ & $0,0 \pm 2,0$ & 70 \\
Europe & $-0,3 \pm 0,8$ & $0,0 \pm 2,0$ & 60 \\
Asia & $-1,5 \pm 0,7$ & $0,0 \pm 2,0$ & 65 \\
Tropics* & $1,0 \pm 1,0$ & $1,6^{*} \pm 1,5$ & 33 \\
South America & $0,1 \pm 0,7$ & $0,6 \pm 0,9$ & 22 \\
Africa & $0,2 \pm 0,6$ & $0,4 \pm 0,9$ & 33 \\
Asıa & $0,8 \pm 0,4$ & $0,6 \pm 0,9$ & 56 \\
& $-0,1 \pm 0,3$ & $0,0 \pm 0,9$ & 68 \\
$20^{\circ} \mathrm{S}-90^{\circ} \mathrm{S}$ & $-1,5 \pm 0,5$ & $-1,2 \pm 3,0$ & 85 \\
& $-1,1 \pm 0,3$ & $-1,0 \pm 0,9$ & 61 \\
Oceans & $-0,3 \pm 0,2$ & $-0,4 \pm 1,0$ & 84 \\
$20^{\circ} \mathrm{N}-90^{\circ} \mathrm{N}$ & $-0,8 \pm 0,3$ & $-0.6 \pm 1,4$ & 79 \\
North Pacific & & & \\
North Ptlantic & $0,6 \pm 0,2$ & $0,8 \pm 1,5$ & 90 \\
& & & \\
Tropıcs* & $-1,0 \pm 0,3$ & $-1,1 \pm 2,1$ & 87 \\
$20^{\circ} \mathrm{S}-90^{\circ} \mathrm{S}$ & $-0,9 \pm 0,3$ & $-0,8 \pm 1,5$ & 83 \\
$20-50^{\circ} \mathrm{S}$ oceans & $-0,1 \pm 0,1$ & $-0,3 \pm 1,5$ & 93 \\
Austral ocean & & & \\
\hline
\end{tabular}

In $\mathrm{Gt}_{\mathrm{yr}^{-1}}$.

* Land use and land uptake have been added in the tropics for both a priori fluxes and a posterion fluxes. A priori land uptake is chosen to be $0.0 \pm 40 \mathrm{Gt} \mathrm{C} \mathrm{yr}^{-1}$ in order not to introduce a bias in the optimized solution A prior deforestation is $1.6 \pm 0.8 \mathrm{Gt} \mathrm{C} \mathrm{yr}^{-1}$. Error represents the dimınution of a posteriori error compared to a priori error (in \%). 
Table 4. Comparison of $S_{0}$ With Other Flux Estimates

\begin{tabular}{lccccccc}
\hline & Global & Tropics & Nontropics & Fossil & Accu. & Years & Major Constraint \\
\hline Keeling et al. $[1989]$ & -2.8 & $1.4+$ & -4.2 & 5.2 & 2.4 & 1984 & $\mathrm{CO} 2$ and $\delta 13 \mathrm{C}$ historical data \\
Oceans & -2.3 & 1.1 & -3.4 & & & & \\
Continents & -0.5 & 0.3 & -0.8 & & & & \\
Tans et al $[1990]$ & -2.3 & $1.8^{+}$ & -3.9 & 5.3 & 3.1 & $1981-1987$ & latidudinal $\mathrm{CO}_{2}$ gradient \\
Oceans & -0.4 & 1.3 & -1.7 & & & & \\
Continents & -1.9 & 0.5 & -2.4 & & & & \\
Ciais et al. $[1995]$ & -4.3 & $1.4^{*}$ & -5.9 & 6.1 & 1.7 & $1992-1993$ & latitudinal $\mathrm{CO}_{2}$ and $\delta^{13} \mathrm{C}_{\text {gradients }}$ \\
Oceans & -1.8 & -0.3 & -1.5 & & & & \\
Continents & -2.6 & 1.7 & -4.3 & & & & \\
Bousquet et al. $[1996]$ & -4.3 & $1.0^{\#}$ & -5.3 & 6.1 & 1.8 & $1992-1993$ & latidudinal $\mathrm{CO}_{2}$ gradient \\
Oceans & - & - & - & & & & \\
Continents & - & - & - & & & & \\
Rayner et al. [1997] & -2.7 & $1.1^{*}$ & -3.9 & 5.9 & - & $1980-1994$ & $\mathrm{CO}_{2}, \delta^{13} \mathrm{C}_{\text {, and } \mathrm{O}_{2} / \mathrm{N}_{2} \text { gradients }}$ \\
Oceans & -1.8 & 1.5 & -3.3 & & & & between monitoring sites \\
Continents & -0.9 & -0.4 & -0.6 & & & & \\
Inversion $S_{0}$ & -2.7 & $1.6^{+}$ & -4.3 & 5.9 & 3.1 & $1990-1994$ & $\mathrm{CO}_{2}$ gradients \\
Oceans & -1.5 & 0.6 & -2.1 & & & & between monitoring sites \\
Continents & -1.3 & 1.0 & -2.2 & & & & \\
\hline
\end{tabular}

In $\mathrm{Gt} \mathrm{yr}^{-1}$. Accu. stands for atmospheric accumulation.

*: Tropical band is $30^{\circ} \mathrm{N}-30^{\circ} \mathrm{S}$.

+ Tropical band is $16^{\circ} \mathrm{N}-16^{\circ} \mathrm{S}$.

\# Tropical band is $20^{\circ} \mathrm{N}-20^{\circ} \mathrm{S}$.

used for direct calculations and the number of observational constraints. Rayner et al. only use $12 \mathrm{CO}_{2}$ atmospheric sites (with constants errors) that have a continuous period of record between 1980 and 1995. Thus their inverse problem is underconstrained and does not fully take into account $\mathrm{CO}_{2}$ gradients between oceans and continents. They also include as additional constraints $\delta^{13} \mathrm{C}$ atmospheric data for Cape Grim [Francey et al., 1995] and the $\mathrm{O}_{2} / \mathrm{N}_{2}$ global trend in the atmosphere which fixes the value of the ocean uptake. Considering the results detailed in Table 4, one can notice that the ratio between the net tropical source and the net extratropical sink is close between the two studies (30-35\%), but this work finds a larger contrast between tropical and nontropical land ecosystems. However, there are major discrepancies for ocean/continent partition. The global ocean sink inferred by Rayner et al. in the extratropical regions $\left(-3.3 \mathrm{Gt} \mathrm{C} \mathrm{yr}^{-1}\right)$ is 5 times as large as the continental sink, whereas they are of the same order of magnitude in our control inversion $S_{0}$. These differences could be explained by the lack of continental influenced sites in the study of Rayner et al. compared with $S_{0}$. These stations, such as Baltic (BAL), Niwot Ridge (NWR), or Ryori (RYO), for instance, strongly determine continent versus ocean $\mathrm{CO}_{2}$ contrast and contribute to the inference of a major continental sink over the continents of the Northern Hemisphere in $S_{0}$. Note that the a priori constraints for global land vs. ocean uptakes are large enough not to nudge the solution.

\section{Optimized Regional Sources and Sinks}

One main advantage of 3-D inversion is that it allows for estimations of the annual fluxes and errors at continental and ocean basin scales. However, before presenting regional results, it is important to check the a posteriori spatial correlation between the regions used for inverse calculation.

\subsection{A Posteriori Spatial Correlations}

The a posteriori coavariance matrix $C_{m}^{\prime}$ can be converted in spatial correlation between the source regions used for the calculation. A significant a posteriori correlation between two sources means that atmospheric measurements cannot separate the two fluxes. In other words, two regions presenting a significative correlation have to be summed in the results because we only infer information about the sum of their fluxes. The sign of the correlation, even if not significative also gives important indications. We use 45 unknowns (regional annual fluxes), but 11 are linked, as the sum of GPP and RES is constrained to be zero annualy. Thus the level of meaning for the 45-11-2=32 degrees of freedom of our problem is $0.45(P=0.01)$. A posteriori correlation between regions are presented in Table 5.

The only sgnificative correlations occur between DEF and BIO_UPT over tropical Asia (-0.58). This means that we cannot separate these two processes in this region. The sign implies that if DEF flux increases, the BIO_UPT flux decreases. For the purpose presentation, we choose to add deforestation source and net land uptake not only in tropical Asia but also in other tropical regions. One can observe some negative insignificant correlations between boreal and temperate regions of the Northern Hemisphere (-0.44 in north Asia). For North America, Europe, and north Asia, results will be presented as the sum of boreal and temperate fluxes.

One can also notice the anticorrelation between seasonal cycle and net uptake over Europe and North America (B6/U6 and B2/U2), which means that somehow a large seasonal cycle induces a large uptake over these two regions. For ocean regions we choose to keep three regions in the Southern Hemisphere and to group the two Pacific regions and the two Atlantic regions together. In conclusion, inferred net fluxes and errors are presented in the following over eight continental and five oceanic regions (Figure 6 and Table 3). 


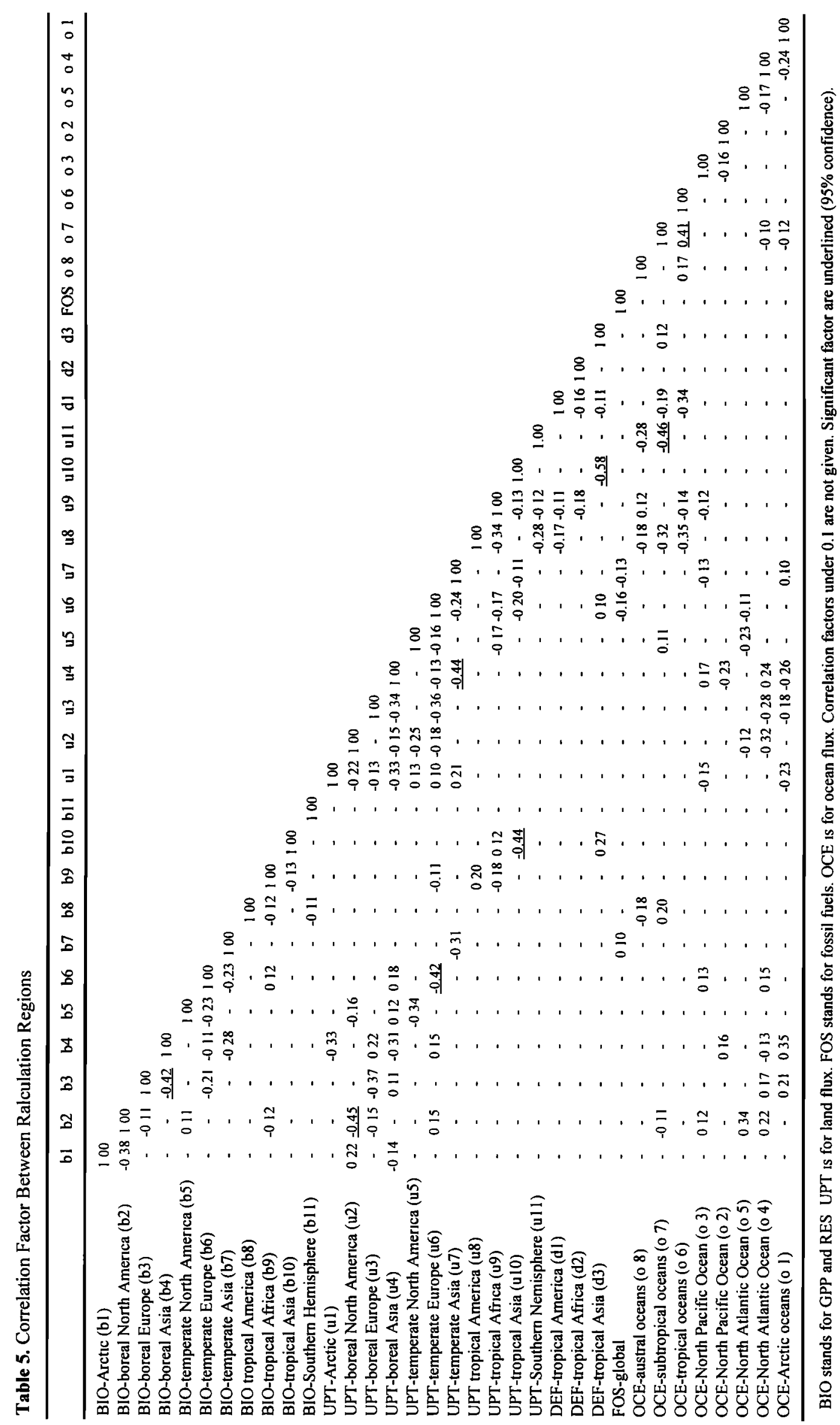



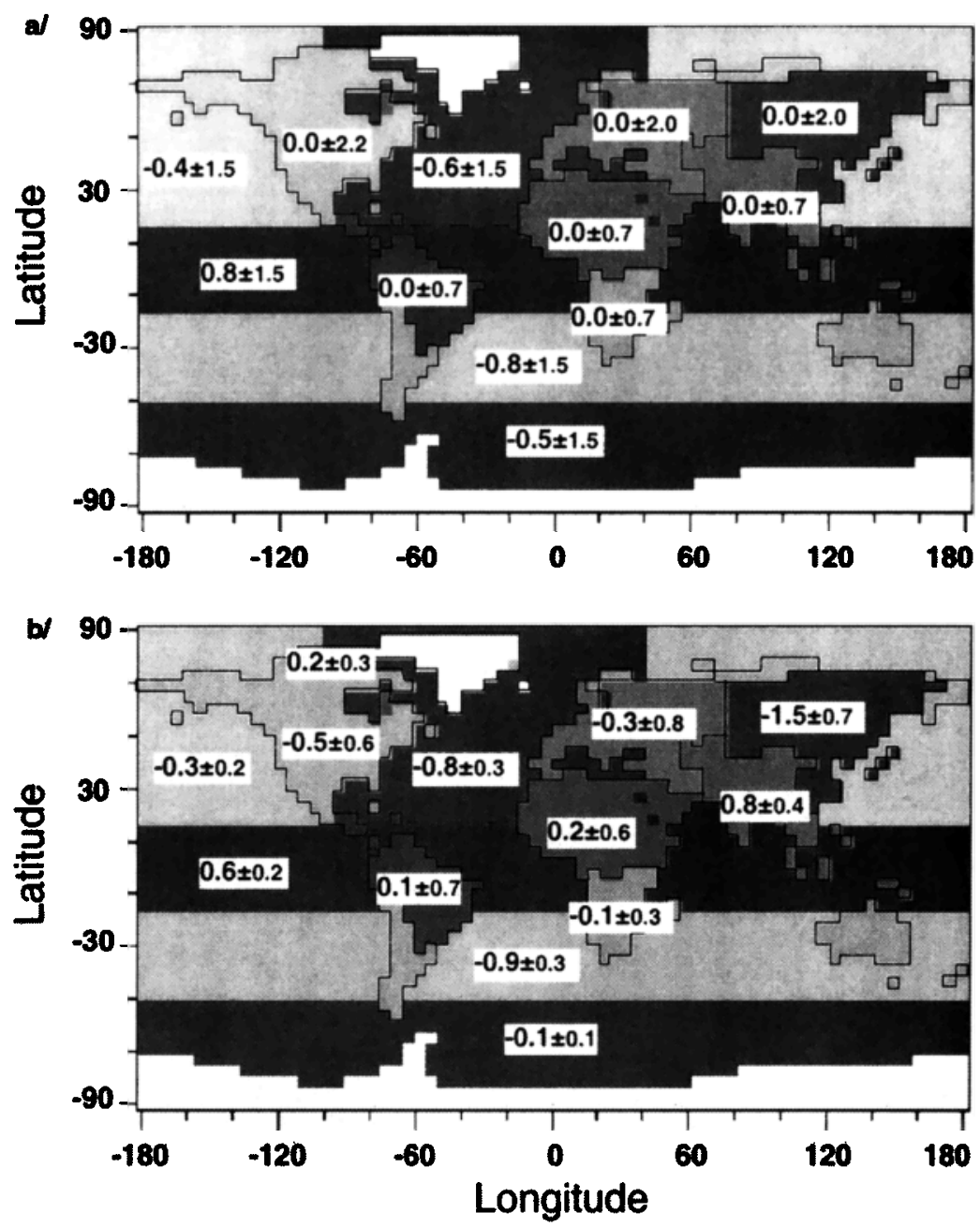

Figure 6. Annual $\mathrm{CO}_{2}$ net fluxes at continental and ocean basin scale. (a) a priori net fluxes and (b) a posteriori net fluxes inferred in the control inversion $S_{0}$. Fluxes and errors are expressed in $\mathrm{Gt} \mathrm{C} \mathrm{yr}^{1}$.

\subsection{Southern Oceans}

We infer an uptake of $0.9 \pm 0.3 \mathrm{Gt} \mathrm{C} \mathrm{yr}^{-1}$ for sub-Antarctic and subtropical waters north of the polar front zone $\left(50^{\circ} \mathrm{S}\right)$ and an uptake of $0.1 \pm 0.1 \mathrm{Gt} \mathrm{C} \mathrm{yr}^{-1}$ south of the polar front zone. The inverse procedure only slightly changes the value of the air-to-sea fluxes over both regions, compared to their a priori estimate. Most studies tend to infer a larger uptake between $15^{\circ} \mathrm{S}$ and $50^{\circ} \mathrm{S}$ than further south. North of the polar front zone, sinks are obtained by Tans et al. [1990] of $1.5 \mathrm{Gt} \mathrm{C} \mathrm{yr}^{-1}$, Keeling et al. [1989] of $0.8 \mathrm{Gt} \mathrm{C} \mathrm{yr}^{-1}$, and Rayner et al. [1998] of $1.8 \mathrm{Gt} \mathrm{C} \mathrm{yr}^{-}$ 1 . Ocean carbon models calculate similar uptake values, 0.6 Gt C yr-1 by Aumont [1998] and in the range 0.6-1.2 Gt C yr-1 by Fan et al. [1998]. South of the polar front, recent studies tend to infer either a small sink (Rayner et al. [1997] of $0.1 \mathrm{Gt} \mathrm{C} \mathrm{yr}^{-1}$ and Aumont [1998] of $0.3 \mathrm{Gt} \mathrm{C} \mathrm{yr}^{-1}$ ) or a small source (Tans et al. [1990] of $0.5 \mathrm{Gt} \mathrm{C} \mathrm{yr}^{-1}$ and Keeling et al. [1989] of 0.1 $\mathrm{Gt}{\mathrm{C} \mathrm{yr}^{-1}}^{-1}$ ). One would notice that the inferred value of the sink found south of the polar front $\left(0.2 \mathrm{Gt} \mathrm{C} \mathrm{yr}^{-1}\right)$ is not affected by the choice of the first guess. If we set this region to be a small

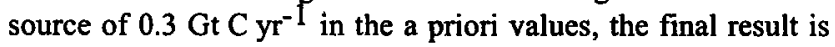
unchanged.

The largest effect of optimizing the air-to-sea fluxes against the atmospheric data over the oceans south of $20^{\circ} \mathrm{S}$ is to reduce the uncertainties from $\pm 1.5 \mathrm{Gt} \mathrm{C} \mathrm{yr}^{-1}(2 \sigma)$ down to \pm 0.3 and $\pm 0.1 \mathrm{Gt} \mathrm{C} \mathrm{yr}^{-1}$ northward and southward respectively of the polar front. This reduction of uncertainties is the most important among all the fluxes that are optimized in $S_{0}$, indicating a fair level of confidence in these estimates. However, the absolute value of the a posteriori error bars may be too optimistic as some uncertainties are not taken into account, especially in the atmospheric transport and the influence of the spatial patterns. This problem is partly addressed by Bousquet et al. [this issue]. Furthermore, the choice of only two latitude bands to describe the southern oceans is somewhat arbitrary, given the fact that $\triangle p \mathrm{CO}_{2}$ measurements and the ocean biological activity exhibit geographic patterns with some variations in longitude [Antoine and Morel, 1996ab; Metzl et al., 1995; Sullivan et al., 1993]. This is corroborated by the fact that small atmospheric $\mathrm{CO}_{2}$ gradients are detected within the same latitude band between Amsterdam Island (AMS) and Cape Grim (CGO), two stations in the western and eastern part of the southern Indian Ocean at $40^{\circ} \mathrm{S}$ [Monfray et al., 1996]. As a sensitivity test, we divided the Indian Ocean region north of the polar front into an eastern part (from $80^{\circ} \mathrm{E}$ to $150^{\circ} \mathrm{E}$ ) and a western part (from $150^{\circ} \mathrm{E}$ to $80^{\circ} \mathrm{E}$ ). This has the effect of increasing the inferred uptake over the whole latitude band by 0.2 $\mathrm{Gt} C \mathrm{yr}^{1}$ and of locating a sink in the eastern half $\left(0.6 \mathrm{Gt} \mathrm{C} \mathrm{yr}^{-1}\right)$ 
stronger than in the western half in order to match the observed CGO minus AMS negative $\mathrm{CO}_{2}$ difference of $0.4 \mathrm{ppm}$. The $\mathrm{CO}_{2}$ sink in the eastern half then corresponds to an average $\triangle p \mathrm{CO}_{2}$ of $-35 \mu$ atm.

\subsection{Equatorial Oceans}

The equatorial ocean source is set to $0.8 \pm 1.5 \mathrm{Gt} \mathrm{C} \mathrm{yr}^{-1}$ in the prior budget, and it is reduced in the control inversion $S_{0}$ to $0.6 \pm$ $0.2 \mathrm{Gt} \mathrm{C} \mathrm{yr}-1$. The important reduction of the uncertainty obtained for this flux gives us a good degree of confidence in this result. However, this estimate of the equatorial sea to air flux is less than the one obtained by Heimann et al. [1989] (1.7 Gt C yr ${ }^{-}$ 1 for 1980s), Tans et al. [1990] (1.6 Gt C yr-1) and Ciais et al. [1995a] between 1991 and $1994\left(1.1 \mathrm{Gt} \mathrm{C} \mathrm{yr}^{-1}\right)$. The equatorial ocean source value is considered as "well-known" as extrapolated from $\Delta p \mathrm{CO}_{2}$ measurements of Keeling et al. [1989] and Tans et al. [1990] and therefore has not been optimized in these two studies. Note also that the estimate of Tans et al. and Keeling et al. excluded the El Niño years when the suppression of the upwelling in the Eastern Pacific certainly reduces the $\mathrm{CO} 2$ outgassing at the equator. We include two major El Niño events in the atmospheric data that are analyzed in $S_{0}$, which may explain why our estimate is lower: $13 \mathrm{ppm}$ on average for the $15^{\circ} \mathrm{N}-15^{\circ} \mathrm{S}$ latitude band as compared with $19.5 \mathrm{ppm}$ found by Keeling et al. [1989].

Recent $\triangle p \mathrm{CO}_{2}$ measurements indicate that upwelling regions over the eastern Pacific and Atlantic are indeed supersaturated in $\mathrm{CO}_{2}$ [Andrie et al., 1986; Boutin and Etcheto, 1997], but the central and western Pacific Ocean may be closer to equilibrium with the atmosphere [Boutin and Etcheto, 1997]. As a sensitivity test, dividing the equatorial ocean region between $15^{\circ} \mathrm{S}$ and $15^{\circ} \mathrm{N}$ into four separate basins in the inversion (western Pacific, eastern Pacific, Atlantic, Indian) places a source region in the eastern Pacific $\left(+0.4 \mathrm{Gt} \mathrm{C} \mathrm{yr}^{-1}\right)$ in good agreement with $\Delta p \mathrm{CO}_{2}$ measurements [Boutin and Etcheto, 1997; Takahashi et al., 1997]. A drawback is that the Indian and western Pacific equatorial zones then tend to absorb $\mathrm{CO}_{2}(-0.2 \mathrm{Gt} \mathrm{C} \mathrm{yr}-1)$, which appears unlikely in view of $\triangle p \mathrm{CO}_{2}$ measurements. This suggests that the atmospheric network does not provide the information to better estimate the fluxes over four separate ocean regions around the equator. Also convective mixing in the ITCZ zone may have a strong effect on the $\mathrm{CO}_{2}$ simulated concentration at the surface, by diluting into the air column $\mathrm{CO}_{2}$ emitted at the surface. Vertical mixing by deep convection and horizontal mixing being correlated, we observed that the "footprint" of the air-to-sea fluxes exchanged over the western Pacific zone, for instance, do not extend largely to the NOAA CMDL stations located in the central Pacific that are used in the inversion.

\subsection{Tropical Continents}

We obtain a net source over the tropical continents of $1.0 \pm$ $1.0 \mathrm{Gt} \mathrm{C} \mathrm{yr} r^{-1}$, as the sum of net biospheric uptake BIO_UPT and net deforestation release DEF. There are strong differences between South America $\left(30^{\circ} \mathrm{S}\right.$ to $\left.10^{\circ} \mathrm{N}\right)$ and Africa $\left(10^{\circ} \mathrm{S}\right.$ to $\left.10^{\circ} \mathrm{N}\right)$, on one hand, and tropical Asia $\left(10^{\circ} \mathrm{S}\right.$ to $\left.30^{\circ} \mathrm{N}\right)$, on the other hand as shown in Figure 6. South America and Africa are both small net sources of $0.1 \pm 0.7$ and $0.2 \pm 0.6 \mathrm{Gt} \mathrm{C} \mathrm{yr}^{-1}$ respectively, which suggests either that the current deforestation source there is overestimated or that it is entirely offset by regional ecosystems regrowth or uptake. The $\mathrm{CO}_{2}$ fluxes inferred for South America and Africa are qualitatively in agreement with the results of Keeling et al. [1996b], who infer from $\mathrm{O}_{2} / \mathrm{N}_{2}$ ratios that tropical continents as a whole cannot be a strong source to the atmosphere. Ciais et al. [1995a] also obtained from ${ }^{13} \mathrm{C} /{ }^{12} \mathrm{C}$ measurements a weak terrestrial sink in the southern tropics but a large, unexplained, terrestrial source in the northern tropics. From high resolution satellite measurements, Skole and Tucker [1993] have analyzed that the deforested area in the Amazon is lower than the one used to produce the IPCC value of $1.6 \mathrm{Gt} \mathrm{C} \mathrm{yr}^{-1}$ [Houghton, 1997]. Furthermore, a recent calculation of the carbon responses to land use changes (clearing and regrowth) in the tropics also suggests that the current deforestation $\mathrm{CO}_{2}$ emissions may be too high [Fung et al., 1997]. Note that our inverse method cannot distinguish between carbon storage by pristine tropical ecosystems and reduced deforestation estimates, as only the net $\mathrm{CO}_{2}$ flux exchanged between land and atmosphere can be constrained by atmospheric $\mathrm{CO}_{2}$ measurements. Finally, in contrast with other tropical land areas, our analysis shows that tropical Asia is a source of $0.8 \pm 0.4 \mathrm{Gt} \mathrm{C} \mathrm{yr}^{-1}$.

The reduction of uncertainties achieved in the inverse procedure for the tropical continents is the weakest among all regions of the globe, especially over South America and Africa. Table 3 indicates a gain of the order of $25 \%$ compared to the prior uncertainties. This illustrates the rather poor level of constraint imposed by the atmospheric network over these regions. However, uncertainties are reduced significantly over tropical Asia (by 60\%), where the fluxes are constrained by several continental and oceanic stations (TAP, C01-7, QPC, GMI).

\subsection{Northern Hemisphere Oceans}

The oceans north of $15^{\circ} \mathrm{N}$ have a net sink of $1.1 \pm 0.3 \mathrm{Gt} \mathrm{C} \mathrm{yr}^{-}$ 1. The Northern Hemisphere ocean uptake is located mainly in the North Atlantic $\left(0.8 \pm 0.3 \mathrm{Gt} \mathrm{C} \mathrm{yr}^{-1}\right)$, whereas the North Pacific has only a weak sink $\left(0.3 \pm 0.2 \mathrm{Gt} \mathrm{C} \mathrm{yr}^{-1}\right)$. The North Atlantic uptake occurs for $60 \%$ at temperate latitudes $\left(15^{\circ}-50^{\circ} \mathrm{N}\right)$ and for $40 \%$ in the Arctic $\left(50^{\circ}-80^{\circ} \mathrm{N}\right)$. This result is based on 10 stations in the Atlantic area, among a total of 80 worldwide. A significant part of the North Atlantic sink is likely due to the southward transport of carbon by the thermohaline circulation, which is estimated to be of $0.4 \mathrm{Gt} \mathrm{C} \mathrm{yr}^{-1}$ [Broeker and Peng, 1992; Keeling et al., 1996b]. There are numerous ocean $\triangle p \mathrm{CO}_{2}$ measurements in the Atlantic [Takahashi et al., 1993; Watson et al., 1991] covering all seasons, but these data are not a strong constraint on the air-to-sea regional fluxes, even after extrapolation, because of a $50 \%$ residual uncertainty in the gas exchange rates. Yet, at the scale of large gyres, geographic differences in fluxes extrapolated from discrete $\Delta p \mathrm{CO}_{2}$ data can be compared to the ones inferred from gradients in atmospheric $\mathrm{CO}_{2}$ concentration. The analysis of Takahashi et al. shows a temperate over Arctic ratio of mean $\Delta p \mathrm{CO}_{2}$ of 0.4 , which is consistent with the objective analysts of similar measurements made by Lefèvre [1995]. The temperate over Artic ratio of our pror fluxes estimates, computed from the Takahashi et al. analysis, is 0.6 , and it becomes 1.5 after inversion. This means that the stronger sink of $\mathrm{CO}_{2}$ is placed predominantly south of $50^{\circ} \mathrm{N}$ in the inversion, opposite to the prior budget computed from $\Delta p \mathrm{CO}_{2}$ measurements. In their inversion, Rayner et al. [1997] also infer a larger sink in the temperate band (temperate over Arctic ratio is 2.3) using three stations in the Atlantic out of a total of 12 .

The North Pacific Ocean is found to take up $0.3 \pm 0.2 \mathrm{Gt} \mathrm{C} \mathrm{yr}^{-}$ 1 , thus about half that of the North Atlantic. There is no deepwater formation in the North Pacific, and no subduction of carbon into the thermocline occurs as in the North Atlantic 
[Follows et al., 1996]. Our sink estimate is less than the one obtained by Rayner et al. [1997] (0.6 Gt C $\left.\mathrm{yr}^{-1}\right)$, who excluded the NOAA CMDL shipboard $\mathrm{CO}_{2}$ measurements in the central Pacific Ocean. We have performed a sensivity test where we remove NOAA CMDL shipboard measurements from the data list. However, the results of this test do not explain the difference that we get from those of Rayner et al. . We examined the covariance between the North Atlantic and the North Pacific inferred fluxes and found no significant correlation $(r<0.1$, Table 5), which indicates that both regions are independently constrained one from the other by the atmospheric network.

The reduction of uncertainties in the inversion is more important over the North Pacific $(68 \%)$ than over the North Atlantic (40\%). Possible explanations are (1) that there are more sites in the North Pacific than in the North Atlantic and (2) that some of the stations constraining the Atlantic fluxes are not properly represented in the TM2 coarse resolution version that we use (BAL, SCH, WES, CIM). These sites possibly bring no additional information for the inversion, or even bring contradictory information with other sites. As a consequence, there is a subspace in the data space, called null space, that cannot be reached from the flux space we choose. In this context, adding sites that cannot be properly represented by the model will not significantly reduce the uncertainties on the fluxes but may rather change the inferred flux extimates. Thus error reduction is not as important as it could be if there were a better coherence between model resolution, spatial and temporal discretization of source base functions, and location of measurement sites.

\subsection{Northern Hemisphere Continents}

We obtain a net sink of $2.1 \pm 1.2 \mathrm{Gt} \mathrm{C} \mathrm{yr}^{-1}$ in the Northern Hemisphere continents, that is, partitioned in North America ($\left.0.5 \pm 0.6 \mathrm{Gt} \mathrm{C} \mathrm{yr}^{-1}\right)$, Europe $\left(-0.3 \pm 0.8 \mathrm{Gt} \mathrm{C} \mathrm{yr}^{\mathrm{l}}\right)$ and northern Asia(-1.5 $\left.\pm 0.7 \mathrm{Gt} \mathrm{C} \mathrm{yr}^{-1}\right)$. The Arctic area is found to be a small

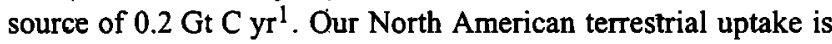
about 1/3 of the sink inferred by Fan et al. [1998], although both estimates almost overlap within errors. Fan et al. [1998] used the global chemical transport model (GCTM) from the Geophysical Fluid Dynamics Laboratory (GFDL) which presents significant differences with TM2 model as shown in TRANSCOM phase II experiment [Denning et al., 1997b]. More precisely, GFDL GCTM presents a stronger rectifier effect above continents than TM2 model. This more intense rectifier effect could require a stronger $\mathrm{CO}_{2}$ sink above continental areas like North America in the GFDL model. Furthermore, they fix the ocean fluxes to a priori values. Our estimate of the North American uptake translates into a net ecosystem production flux (NEP) of 25 $\mathrm{g} \mathrm{C} \mathrm{m}^{-2} \mathrm{yr}^{-1}$ compared to a net primary production(NPP) of $\sim 300 \mathrm{~g} \mathrm{C} \mathrm{m}^{-2} \mathrm{yr}^{-1}$ [Esser et al., 1997]. Thus the net storage of $\mathrm{CO}_{2}$ constitutes a $<10 \%$ fraction of the NPP. We infer a large sink of $1.5 \mathrm{Gt} \mathrm{C} \mathrm{yr}^{-1}$ in northeast Asia from the atmospheric observations. This translates into a NEP of $75 \mathrm{~g} \mathrm{C} \mathrm{m}^{-2} \mathrm{yr}^{-1}$, whereas NPP estimates range from 200 to $800 \mathrm{~g} \mathrm{C} \mathrm{m}^{-2} \mathrm{yr}^{-1}$ between $40^{\circ} \mathrm{S}$ and $65^{\circ} \mathrm{N}$ in Siberia [Esser et al., 1997]. Thus the NEP that we obtain is a fraction of the order of $10-30 \%$ of the NPP.

The atmospheric network density is very low over Siberia and eastern Europe. First, we need to examine whether the sink in Asia is correlated by the inverse procedure to uptake elsewhere in the Northem Hemisphere, via the atmospheric transport which mixes air more rapidly in longitude than in latitude. We verify from the a posteriori covariance matrix in Table 5 that this is not the case. Second, we look at possible correlation between fluxes in northeast Asia (net sink) and in tropical Asia (net source). We could suspect fluxes inferred over these two adjacent regions to be anticorrelated because they are opposite in sign and comparable in magnitude. The degree of correlation among these two regions should furthermore depend on the stations used in the inversion. We do not find any significant correlation in the a posteriori covariance matrix between the two Asian regions (Table 5). Moreover, we have previously shown that the Asian tropical source is primarily constrained by the China Sea boat measurements nearby, independently of the northern Asian sink, which does not change when we remove the China Sea sites from the data set. Third, we observe that the Japanese vertical profiles data (S01-05; data from Tanaka et al., [1987]) strongly constrain the partition of the land uptake among boreal Asia and temperate Asia (two subregions of the northern Asian region in Figure 2) but independently of what happens in the tropics. Thus we cannot find any evidence that the two northern and tropical Asian regions are anticorrelated.

Rayner et al. [1997] have inferred a net sink of $\mathrm{CO}_{2}$ over Asia (tropical plus north) of $0.5 \pm 0.8 \mathrm{Gt} \mathrm{C} \mathrm{yr}^{-1}$, close to this work

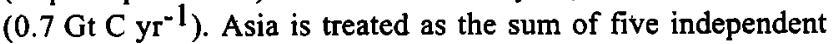
subregions, but opposite to our finding, each region absorbs the same quantity of carbon, and the sink over Asia is almost uniformly distributed between the ropics and the mid to high latitudes. An explanation for the difference between the study of Rayner et al. and this work could again be the number of stations used for the inversion. Rayner et al. [1997] use 12 sites in their study, none of which was located close to the Asian continent. The net flux that we calculate over Asia in $S_{0}$ is constrained more directly by Asian sites (TAP, QPC, UUM) as well as stations in the northwestern Pacific (RYO, SHM, and vertical profiles over Japan S0-5). Yet we do not include any measurement directly made over Siberia. However, many measurement sites are located directly downwind of Siberia and contribute to constrain this region considering (1) the westerlies dominating air flow at these latitudes and (2) the fact that the TM2 model mixes $\mathrm{CO}_{2}$ emitted over Siberia rather efficiently both in the zonal and meridional direction by intrahemispheric transport patterns [Law et al., 1996].

The uncertainties on the inferred continental fluxes are reduced by $70 \%$ compared to the a priori value of $\pm 2 \mathrm{Gt} \mathrm{C} \mathrm{yr}^{-1}$ $(2 \sigma)$ that was assigned to each region of North America, Europe, and northern Asia (Table 3). The most important reduction is achieved for North America, where the a priori error drops down to $\pm 0.6 \mathrm{Gt} \mathrm{C} \mathrm{yr}^{-1}$. A site of particular importance there is NWR ( $3500 \mathrm{~m}$ above sea level) located in the middle of the United States. Removing NWR implies an increase of the global land

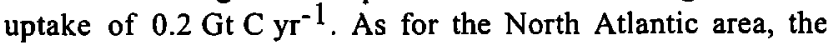
minimum of reduction is obtained over Europe $(60 \%)$ despite a large density of sites there. There is probably a problem of coherence between the small number of source base functions that we choose over Europe, the model coarse resolution, and the relative proximity of continental stations over Europe. Furthermore, continental high-altitude sites are especially difficult to model. For instance, the $\mathrm{CO}_{2}$ data are selected carefully at Schauinsland ( $\mathrm{SCH} ; 1500 \mathrm{~m}$ above sea level) during nightime in order to minimize contamination by local sources, a criterion not reproduced in our study. Even more problematic is Monte Cimone (CIM; $2300 \mathrm{~m}$ above sea level) which has an absolute minimum of $\mathrm{CO}_{2}$ within its latitude band. One may attribute the very low $\mathrm{CO}_{2}$ values recorded at $\mathrm{CIM}$ in summertime to vegetation activity nearby, whereas the wintertime $\mathrm{CO}_{2}$ concentrations are closer to the marine baseline. 
As a sensitivity test, removing CIM from the sites used in the inversion would double the land uptake over Europe with a sink of $0.6 \mathrm{Gt} \mathrm{C} \mathrm{yr}-1$. A specific, more accurate modeling of continental $\mathrm{CO}_{2}$ records is beyond the scope of this global study but should be addressed carefully in the future.

\section{Limitations of the Method}

The results presented and discussed in this paper have been obtained for one set of a priori fluxes, using one configuration of the atmospheric network, running one atmospheric transport model and optimizing the fluxes with one annual inverse procedure. Some hypotheses made for the inverse calculation are strong hypotheses, such as the perfection of atmospheric transport. Accounting for error in the transport would probably significatively increase the a posteriori uncertainties that are clearly underestimated for some regions (tropical oceans, for instance).

As we optimize only annual strengths for all fluxes, the phase of the a priori simulated seasonal cycle can only be slightly changed. Thus it is difficult to catch when SIB2 model, or transport model are wrong. The result is that considering the phase of atmospheric $\mathrm{CO}_{2}$ concentrations, SIB2 and TM2 do not perform too bad at mid and high latitudes of the Northem Hemisphere. However, in the tropics there are some sites where the phase of the signal cannot be matched (see Figure 3). In these conditions, there is a risk that the inverse procedure is more likely interpreting models biais than $\mathrm{CO}_{2}$ signal as noticed before. Another limitation is the sensitivity of the method to the prior estimates of the fluxes and errors. Spatial patterns of the initial fluxes are prescribed in our approach and cannot be modified within each region by the inverse procedure. The choice of a priori errors is mostly arbitrary which may have an influence on the inferred fluxes for poorly constrained regions. This problem is critical for the validity of the estimates in the tropics where few atmospheric stations are available. For flux estimates over north Asia, where few continental sites are present, the validity of the a posteriori estimates could also be criticized. However, some marine or coastal Pacific sites can rather efficiently constrain Siberia fluxes (SHM, RYO, TAP, KSN, CBA) because of the strong zonal transport of air at mid and high latitudes. This assumption is model-dependent.

Another problem that could raise from our climatological approach is the representativness of an average flux estimate over the 1985-1995 decade. Under the hypothesis of a constant atmospheric transport it can be prooved from equation (5) that the vector $\mathbf{m}$ that we calculate with our approach is the average of all vectors $\boldsymbol{m}$, that would be calculated for each individual year $j$ of the decade. We have checked this result by optimizing all fluxes using five 2-year average of atmospheric data (1985-1987, 1988$1989,1990-1991,1992-1993,1994-1995)$, instead of the 10-year climatology. We have verified that the solution inferred with the 10 -year climatology is the mean of 2 -year solutions within \pm 0.1 $\mathrm{Gt} \mathrm{C} \mathrm{yr}^{-1}$ for each regions. The result is not exact because there are small changes in $\boldsymbol{m}_{p}$ vector (the offset is not exactly the average of all offsets) and in $\boldsymbol{C}_{\boldsymbol{d}}$ matrix.

Finally, the choice of observation sites raises also several problems. Some stations cannot be adequatly modeled given the spatial resolution of the a priori fluxes (1 month) and the coarse horizontal grid of TM2 model. This is the case for sites that are located either close to strong sources and sinks or largely above sea level. For instance, fossil emissions or terrestrial biology activity near some continental stations like BAL or WES or TAP are averages of the model grid box and do not reflect actual local fluxes. Also, we do not account for the selection of model outputs as it is done most measurement sites [Ramonet et al., 1996]. However, our strategy is, as a first step, to use all the available atmospheric information for the inverse calculation. The aim is not to convince the reader that we have the unique solution of the problem but to bring an approach of the estimation of annual $\mathrm{CO}_{2}$ fluxes considering one particular inverse method that we describe in detail. In a second step, the influence of the parameters of the inverse procedure on the inferred fluxes can be studied as sensitivity tests [Bousquet et al., this issue].

\section{Conclusion}

In this paper we present a 3-D Bayesian inverse methodology to infer annual net $\mathrm{CO}_{2}$ sources and sinks using atmospheric measurements of $\mathrm{CO}_{2}$, a first guess of fluxes, and the 3-D atmospheric transport model TM2. Inferred fluxes are presented for the control inversion $S_{0}$ at the spatial scale of continents and ocean basins. Inverse procedure is based on the work of Enting et al. [1993] and Tarantola [1987]. Forty-five continental and oceanic source base functions have been run in the TM 2 model. The distance between modeled output concentrations and stationary observations at 77 monitoring sites has been minimized at a least squares sense in order to optimize annual strengths of $\mathrm{CO}_{2}$ sources and sinks. Stationary observations have been calculated for the 1985-1995 decade from GLOBALVIEW$\mathrm{CO}_{2}$ data set [Masarie and Tans, 1995].

At a global scale we infer a global net land uptake of

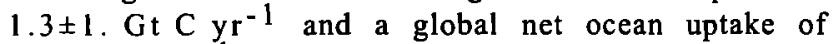
$1.5 \pm 0.5 \mathrm{Gt} \mathrm{C} \mathrm{yr}^{-1}$. At mid and high latitudes of the Northern Hemisphere, lands take up $2.1 \mathrm{Gt} \mathrm{C} \mathrm{yr}^{-1}$ and ocean takes up $1.1 \mathrm{Gt} \mathrm{C} \mathrm{yr}^{-1}$. In the tropics, lands are a source of $1.0 \mathrm{Gt} \mathrm{C} \mathrm{yr}^{-1}$ and ocean is a source of $0.6 \mathrm{Gt} \mathrm{C} \mathrm{yr}^{-1}$. In the Southern Hemisphere, lands are a small sink of $0.1 \mathrm{Gt} \mathrm{C} \mathrm{yr}^{-1}$, whereas

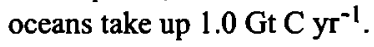

A key point in our methodology is its ability to use longitudinal information in atmospheric concentrations to partition sources and sinks (1) between ocean basins and continents and (2) inside continents. For the Northern Hemisphere, we find a large sink of $1.5 \pm 0.7 \mathrm{Gt} \mathrm{C} \mathrm{yr}^{-1}$ over north Asia, whereas North America and Europe have small sinks of 0.5 and $0.3 \mathrm{Gt} \mathrm{C} \mathrm{yr}^{-1}$ respectively. For the oceans the Northern Hemisphere sink is put preferentially in the North Atlantic Ocean $\left(0.8 \pm 0.3 \mathrm{Gt} \mathrm{C} \mathrm{yr}^{-1}\right)$ compared to the North Pacific Ocean $\left(0.3 \pm 0.2 \mathrm{Gt} \mathrm{C} \mathrm{yr}^{-1}\right)$. In the tropics, the continental source is mainly due to tropical Asia $\left(0.8 \pm 0.4 \mathrm{Gt} \mathrm{C} \mathrm{yr}^{-1}\right)$, whereas tropical Africa and tropical America are neutral $\left(0.1 \pm 0.7 \mathrm{Gt} \mathrm{C} \mathrm{yr}^{-1}\right.$ and $0.2 \pm 0.7 \mathrm{Gt} \mathrm{C} \mathrm{yr}^{-1}$ ). The level of confidence on these tropical fluxes is weak as error bars remain large due to the poor level of constraints imposed by the atmospheric network at these latitudes. South of $15^{\circ} \mathrm{S}$, ocean sink is preferentially found in the

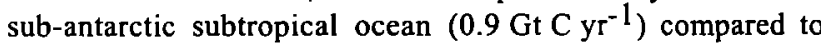
austral ocean, which remains almost neutral.

In section 6, we mentioned the limitations of such an inverse method to infer regional sources and sinks of $\mathrm{CO}_{2}$. One of the important questions raised by inverse methodology is the sensivity to the numerous parameters involved in the calculations. This question has to be fully addressed if one wants to somehow validate the inferred solution presented here in $S_{0}$. In the companion paper (this issue), a sensivity study on the inverse fluxes inferred in the control inversion $S_{0}$ is presented and discussed. This second step seems essential in all inverse 
approaches which should not be considered without that kind of validation.

\section{Appendix A: Atmospheric Data Treatment Procedure}

We describe the procedure to calculate a 12 -month average $C_{i}(t)$ of atmospheric $\mathrm{CO}_{2}$ at each measurement site $i$, in four step according to Thoning et al. [1989]:

$$
C_{i}(t)=A_{i}+B\left(t-t_{\mathrm{mid}}\right)+\operatorname{Seas}_{i}(t)
$$

1. A second-order polynomial trend is removed from GLOBALVIEW-CO 2 smooth time series for the 1985-1995 period. This allows definition of a detrended seasonal cycle for the reference period which exhibits interannual variations. $\operatorname{Seas}_{l}(t)$ is the monthly average of the smoothed $\mathrm{CO}_{2}$ concentration record, as obtained by the curve fitting procedure use to smooth the flask data in GLOBALVIEW-CO [Thoning et $^{2}$ al., 1989; Masarie and Tans, 1995]. For example, Seas, $(t)$ for January is the available average between January 1st and January 31 st for each year between 1985 and 1995.

2. To calculate $A_{j}$, we evaluate the mean difference between annual concentration at station $\mathrm{i}$ and annual concentration at South Pole Station (SPO) for the 1985-1995 period. This difference is then added to the January 1990 mean concentration at SPO to obtain $A_{j}$. This offset of the concentration with SPO concentration is arbitrary and has no impact on the result of the inversion since the optimization of a global offset is also performed by the inversion procedure.

3. The quasi-stationary assumption made for this timeindependent inversion implies a globally uniform annual increase in the $\mathrm{CO}_{2}$ mixing ratio. It means that we take the same value of $B$ for all sites retained by the inversion. $B$ is thus calculated as the global average of the time trends for each measurement site. For the reference period we find that $B=1.4 \pm 0.1 \mathrm{ppm} \mathrm{yr}^{1}$. The uncertainty on $B$ is chosen according to Conway et al. [1994].

4. The standard deviation $\sigma_{d, i}(t)$ of each monthly mean value is calculated as the root-mean-square residual between individual flasks measurements and the fitted smoothed curve. In so, the uncertainties on measurements contain both short-term and longterm variability. In order to account for experimental errors and possible intercalibration problems, we systematically add $0.3 \%$ $\mathrm{Gt} \mathrm{C}$ for $\mathrm{CO}_{2}$ and $0.03 \%$ for $\sigma_{d, i}(t)$ values. As errors on a priori fluxes generally refer to $2 \sigma$ errors in a Gaussian meaning, the observational uncertainties used to fill error matrix also multiply by a factor of 2 each standard deviation $\sigma_{d, l}(t)$.

\section{Appendix B: Description of the A Priori Flux Scenario}

We fully describe the fluxes used as the a priori scenario in our inversion both for all the sources and sinks cited in section 3 .

\section{B1. Fossils(FOS)}

The space-time distribution of fossil fuel emissions is taken from Andres et al. [1997]. It is based on annual estimates of the $\mathrm{CO}_{2}$ emissions due to fossil fuel burning and cement production. We have included a seasonal variation according to the work of Rotty [1987]. The global mean value for the 1985-1995 period is set to $5.9 \pm 0.3 \mathrm{Gt} \mathrm{C} \mathrm{yr}^{1}$ [Marland et al., 1997], the standard deviation corresponding to $5 \%$ of the total (see Table B1).
Table B1. Anthropic Regions and Fluxes

\begin{tabular}{lcc}
\hline \multicolumn{1}{c}{ Process } & Flux & Error \\
\hline Global fossil fuels & 5.9 & 0.3 \\
American land use & 0.6 & 0.6 \\
Africa land use & 0.4 & 0.4 \\
Asia land use & 0.6 & 0.6 \\
\hline
\end{tabular}

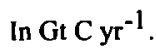

\section{B2. Land Fluxes (GPP, RES, BIO_UPT and DEF)}

Biotic fluxes are gross primary production (GPP), total ecosystem respiration (RES), net uptake (BIO_UPT), and land use changes (DEF). The space-time distribution of GPP and RES is taken from the SIB2 biospheric model which is fully described by Denning et al. [1996] and Sellers et al. [1996a]. Brief summary surface flux calculation is given by Ciais et al. [1997]. Roughly, SIB2 estimates that net assimilation rate on any pixel of land as the minimum of three photosynthetic rates minus the dark respiration: the Rubisco-limited rate, the light-limited rate, and the sink-limited rate. This estimate is based on the work by Ball [1988], Collatz et al. [1991,1992], and Farquhar et al. [1989]. Autothrophic respiration is a function of Rubisco rate and canopy temperature [Sellers et al., 1996a]. Soil respiration is expressed as a Q10 of the temperature according to the method of Raich and Schlesinger [1992]. GPP and total ecosystem respiration (RES) are adjusted for the sum GPP+RES to be zero annually on each pixel of land. Annual means of GPP and errors are given in Table B2.

Net annual uptake by land ecosystems (BIO_UPT) is represented by an explicit annual space distribution given by

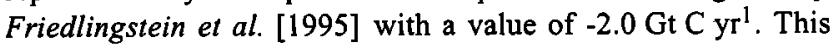
pattern differs mainly from GPP distribution because of a spatial redistribution of flux from tropical regions to Northern Hemisphere continents to account for $\mathrm{CO}_{2}$ and nitrogen fertilization of midlatitude ecosystems. The spatial pattern for BIO_UPT is distributed in time according to SIB2 GPP time variations to produce monthly fields for land uptake. In the inversion, we use BIO_UPT pattern to account for land uptake, but we set to $0.0 \mathrm{Gt} \mathrm{C} \overline{y r}^{1}$ the a priori value of the land uptake for each source base function with a large standard deviation (Figure 6a). This is to limit the bias introduced by a priori flux values on the result of the inversion. The deforestation $\mathrm{CO}_{2}$ source is taken from monthly maps of Houghton [1997] with a global annual value of $1.6 \pm 1.0 \mathrm{Gt} \mathrm{C} \mathrm{yr}^{1}$ (Table B1). Deforestation flux is based on changes in the land use and thus includes biospheric regrowth after destruction.

Over tropical continents the inverse procedure may misallocate land uptake versus deforestation source. Considering the weak constraints imposed by the atmospheric network over tropical land areas (Africa, South America), these fluxes cannot be resolved separately by the inversion. As a result, we only present the net biospheric flux, which is the sum of land uptake and land use release. However, the information of different space-time distribution for uptake and deforestation is a constraint that can be used for inverse calculation.

GPP, RES and BIO_UPT are subdivided into 11 regions (Figure 2 and Table B2). DEF is subdivided into three regions. These determine 36 source base functions for $\mathrm{CO}_{2}$ land fluxes. 
Table B2. Biotic Regions Used for the Inversion

\begin{tabular}{lcccc}
\hline \multicolumn{1}{c}{ Biotic Region } & GPP Flux & Error & Net Uptake & Error \\
\hline Arctic & 0.9 & 0.6 & 0.0 & 0.5 \\
Boreal North America & 5.3 & 2.8 & 0.0 & 1.5 \\
Boreal Europe & 2.6 & 1.7 & 0.0 & 1.5 \\
BorealAsia & 4.6 & 3.2 & 0.0 & 1.5 \\
Temperate North America & 5.9 & 3.0 & 0.0 & 1.5 \\
Temperate Europe & 5.2 & 3.5 & 0.0 & 1.5 \\
Temperate Asia & 4.9 & 3.3 & 0.0 & 0.5 \\
Tropi cal South America & 24.3 & 11.0 & 0.0 & 0.5 \\
Tropical Africa & 5.2 & 6.3 & 0.0 & 0.5 \\
Tropical Asia & 8.8 & 4.9 & 0.0 & 0.5 \\
South of 30 S & 21.6 & 10.3 & 0.0 & 0.5 \\
Total & 100.0 & 20.0 & 0.0 & 3.6 \\
\hline
\end{tabular}

Annual gross and net biotic fluxes, used as a first guess in the inversion. Gross flux spatiotemporal patterns are given by Sellers et al.. [1996a,b]. Net flux spatial patterns are given by Friedlingstein et al., [1995]. Annual net a priori land fluxes are set to 0.0 with a large error bar in order not to

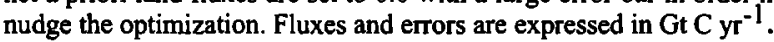

No source base function is associated to disequilibrium with soils because this flux is optimized with total respiration as explained in section 2 . The choice of the regions is mainly arbitrary but can be considered as a compromise between (1) increasing the number of regions in order to limit the influence of spatial patterns within one single region, (2) the spatial constraints imposed by the atmospheric network, and (3) the transport model resolution. Thus we determine six Northern Hemisphere regions (two in North America, two in Europe, and two in north Asia) three tropical regions (South America, Africa, and Asia), and only one southern continental area to take into account the sparseness of the network in this hemisphere. Only the three tropical regions among 10 are considered for land use: South America, Africa and Asia.

\section{B3. Ocean Fluxes (OCE)}

Air-sea $\mathrm{CO}_{2}$ fluxes are represented for each region of the oceans based on monthly maps of $\Delta p \mathrm{CO}_{2}$ inferred by Takahashi et al. [1997]. These maps are calculated using an extrapolation of observed $\triangle p \mathrm{CO}_{2}$ data based on horizontal transport characteristics of a three-dimensional ocean transport model. The net air-sea flux $F_{o}$ is expressed as

Table B3. Oceanic Regions Used for the Inversion.

\begin{tabular}{lcc}
\hline Oceanic regions & Net Flux & Error \\
\hline Austral ocean & -0.3 & 1.5 \\
$20^{\circ} \mathrm{S}-50^{\circ} \mathrm{S}$ oceans & -0.8 & 1.5 \\
Tropical oceans & 0.8 & 1.5 \\
North Pacific $15-45^{\circ} \mathrm{N}$ & -0.2 & 1.0 \\
North Pacific $45-60^{\circ} \mathrm{N}$ & -0.1 & 1.0 \\
North Atlantic $15-50^{\circ} \mathrm{N}$ & -0.3 & 1.0 \\
North Atlantic $-50-80^{\circ} \mathrm{N}$ & -0.4 & 1.0 \\
North of $60^{\circ} \mathrm{N}$ (not Atlantic) & -0.0 & 1.0 \\
Total & -1.2 & 3.0 \\
\hline
\end{tabular}

Annual net oceanic fluxes and errors used as a first guess in the inversion. Net flux spatio-temporal patterns are given by Takahashi et al. [1997]. Fluxes and errors are expressed in Gt ${\mathrm{C} \mathrm{yr}^{-1}}^{-1}$.

$$
F_{\mathrm{o}}=K_{\mathrm{ex}} \Delta p \mathrm{CO}_{2}
$$

where $K_{e x}$ is the exchange coefficient calculated with Liss and Merlivat's [1986] formulation corrected by Heimann and Monfray [1989] and Etcheto et al. [1991]. We use ECMWF wind fields for the year 1990 to calculate $K_{e x}$, with a 12-hour timestep. The global value of $K_{e x}$ has been calibrated on ${ }^{14} \mathrm{C}$ penetration coefficient in the oceans [Broecker et al., 1985] to a value of $0.06 \mathrm{~mol} \mathrm{~m}^{-2} \mathrm{yr}^{1} \mu \mathrm{atm}^{1}$. The global annual flux $F_{o}$ obtained in that manner is $-1.2 \mathrm{Gt} \mathrm{C} \mathrm{yr}{ }^{1}$. Again we assign a large uncertainty to this flux $\left( \pm 3.0 \mathrm{GtC} \mathrm{yr}^{\mathrm{l}}\right)$ to let the inverse procedure calculate its optimized value with little limitation.

The ocean is divided in eight regions determining eight source base functions for net $\mathrm{CO}_{2}$ fluxes that are summarized in Table B3. We take one region for the Southern Ocean south of $50^{\circ} \mathrm{S}$, one for sub-Antarctic subtropical oceans $\left(15^{\circ} \mathrm{S}-50^{\circ} \mathrm{S}\right)$, one for equatorial oceans, two for Pacific Ocean north of $15^{\circ} \mathrm{N}$, two for North Atlantic Ocean north of $15^{\circ} \mathrm{N}$, and one for the oceans north of $75^{\circ} \mathrm{N}$. This partition mainly reflects the density of the present atmospheric network shown on Figure 2. It is also driven by some evident consideration like the separation of North Atlantic and North Pacific and from the structure of the $\triangle p \mathrm{CO}_{2}$ field. The equatorial oceans are known to be a $\mathrm{CO}_{2}$ source [Wong et al., 1993], while the subtropical gyres are thought to be net $\mathrm{CO}_{2}$ sinks [Metzl et al., 1995]. Moreover, the $\Delta p \mathrm{CO}_{2}$ data over the North Atlantic Ocean reveal two distinct zones where $\mathrm{CO}_{2}$ is either on average supersaturated or undersaturated [Takahashi et al., 1997], which has guided our choice of two regions to account for north Atlantic in the inversion.

Acknowledgments. M.Heimann (MPI - Iena) is to be thanked for providing LSCE with both TM2 and TM3 models. This work is supported by the Programme National d'Etude de la Dynamique du Climat (PNEDC) and the Commission of the European Community under contracts ENV4CT95 and ENV4-Euro-Siberian Carbon Flux. Computing support was provided by Commisariat à l'Energie Atomique (CEA). This is contribution 154 of the LSCE.

\section{References}

Andres, R.J., G. Marland, T. Boden, and S. Bishoff, Carbon dioxide emissions from fossil fuel combustion and cement manufacture 17511991 and an estimate of their isotopic composition and latitudinal distribution, in The Carbon Cycle, edited by T.M. Wigley, p.23-32, Cambridge Univ. Press, New York, 1993.

Andres, R.J., G. Marland, T. Boden, and S. Bischoff, Carbon Dioxide Emissions From Fossil Fuel Consumptıon and Cement Manufacture, Cambridge Univ. Press, New York, 1997.

Andrie, C., C. Oudot, C. Genthon, and L. Merlivat, $\mathrm{CO}_{2}$ fluxes in the tropical Atlantic during FOCAL crusses, J. Geophys. Res., 9/(C10), $11,741-11,755,1986$

Antoine, D., and A. Morel, Oceanic primary production, 1, Adaptation of a spectral light-photosynthesis model in view of application to satellite chlorophyll observations, Global Biogeochem. Cycles, 10(1), 43-55, 1996a.

Antoine, D., and A. Morel, Oceanic primary production, 2, Estimation at global scale from satellite (coastal zone color scanner) chlorophyll, Global Biogeochem. Cycles, IO(1), 57-69, $1996 \mathrm{~b}$.

Aumont, O., Etude du cycle naturel du carbone dans un modele trıdimensionnel de l'océan mondial, Ph.D. thesis, Univ. Paris VI, Paris, 1998.

Ball, J T., An analysis of stomatal conductance, Ph.D. thesis, Standford Unıv., Stanford, Calıf, 1988.

Bousquet, P., P. Ciais, P. Monfray, Y. Balkanski, M. Ramonet, and P. Tans, Influence of two atmospheric transport models in inferring sources and sinks of atmospheric $\mathrm{CO}_{2}$, Tellus, Ser. B, 48, 568-582, 1996.

Bousquet, P., P. Peylin, P. Ciais, M. Ramonet, and P. Monfray, Inverse modelling of annual atmospheric $\mathrm{CO}_{2}$ sources and sinks, 2, Sensitivity study, J. Geophys. Res., this issue. 
Boutın, J., and J Etcheto, Long-term variability of the air-sea $\mathrm{CO}_{2}$ exchange coefficient Consequences for the $\mathrm{CO}_{2}$ fluxes in the equatorial Pacific Ocean, Global Bıogeochem. Cycles, 1/(3), 453-470, 1997.

Broecker, W.S., and T.H Peng. Interhemispheric transport of carbon dioxide by ocean circulation, Nature, 356, 587-589, 1992.

Broecker, W.S., T.H Peng, G. Ostlund, and M. Stuiver, The distribution of bomb radiocarbon in the ocean, $J$ Geophys. Res., 90(C4), 69536970,1985

Ciass, P., P P. Tans, M Trolier, J W. White, and R. Francey, A large Northern Hemisphere terrestrial $\mathrm{CO}_{2}$ sink indicated by the ${ }^{13} \mathrm{C}^{12} \mathrm{C}$ ratio of atmospherıc $\mathrm{CO}_{2}$, Science, 269, 1098-1102, 1995a.

Cials, P., P.P. Tans, J W White, M. Trolier, R. Francey, J.A. Berry, D. Randall, P.J. Sellers, J.G. Collatz, and D S Schimel, Partitıoning of ocean and land uptake of $\mathrm{CO}_{2}$ as inferred by $\delta^{13} \mathrm{C}$ measurements from the NOAA Climate Monitorıng and Diagnostic Laboratory global air sampling network, $J$ Geophys Res., $100(\mathrm{D} 3), 5051-5070,1995 \mathrm{~b}$.

Ciais, $\mathrm{P}$, et al., A three dimensionnal synthesis study of $\delta^{18} \mathrm{O}$ in atmospheric $\mathrm{CO}_{2}$, 1, Surface fluxes, $J$ Geophys. Res., 102(D5), 5857$5871,1997$.

Collatz, G.J., J.T. Ball, C. Grivet, and J.A. Berry, Physiological and environmental regulation of stomatal conductance, photosynthesis and transpiration: A model that includes a laminar boundary layer, Agric For Meteorol, 54, 107-136, 1991.

Collatz, G.J., M. Riobas-Carbo, and J.A Berry, Coupled photosynthesisstomatal conductance mbdel for leaves of C4 plants, Aust. J Plant. Physiol , 19, 519-538, 1992.

Conway, T J., P.P. Tans, L.S. Waterman, K W. Thoning, D.R. Kitzis, $\mathrm{K} \mathrm{A}$ Masarie, and N. Zhang, Evidence for interannual variability of the carbon cycle from the National Oceanic and Atmospherıc Admınistratıon/Climate Monitoring and Diagnostic Laboratory Global Air Sampling Network, J. Geophys. Res , 99(D11), 22,831-22,855, 1994.

Cooperative Atmospherıc Data Integration Project: Carbon Dioxide, GLOBALVIEW- $\mathrm{CO}_{2}$, Cooperative Atmospheric Data Integration Project-Carbon Dioxide, CD-ROM, NOAA Clim. Monit. and Diag. Lab., Boulder, Colo., 1997 (Also available via anonymous FTP to ftp.cmdl.noaa gov, Path: ccg/CO /GLOBALVIEW).

Denning, A S , I.Y. Fung, and D.A. Randall, Latitudinal gradient of atmospheric $\mathrm{CO}_{2}$ due to seasonal exchange with land biota, Nature, 376, 240-243, 1995.

Denning, G. J. Collatz, C. Zhang, D. A. Randall, J. A Berry, P. J. Sellers, G. D. Colello, and D. A. Dazlich, Simulation of terrestrial carbon metabolism and atmospheric $\mathrm{CO} 2$ in a general circulation model, Part 1: Surface carbon fluxes, Tellus, 48B, 521-542, 1996.

Denning, A S., et al., Intercomparison and calibration of global tracer transport simulations of SF6, paper presented at Fifth International Carbon Dioxide Conference, Commonwealth Sci. and Ind. Res. Org., Caims, Australia, 1997a

Dennıng, A.S., P.P. Tans, T. Takahashi, P. Friedlingstein, I.Y. Fung, and C.B. Field, Simulation of observed atmospheric $\mathrm{CO}_{2}$ : Evaluation of terrestrial and marine carbon flux scenarios, paper presented at Fifth International Carbon Dioxide Conference, Commonwealth Sci. and Ind. Res. Org., Caurns, Australia, 1997b.

Enting, I.G , and J V. Mansbridge, Latitudinal distribution of sources and sinks of $\mathrm{CO}_{2}$. Results of an inversion study, Tellus, Ser. B, 43, 156170, 1991

Enting, I.G , C.M. Trudinger, R.J. Francey, and H. Granek, Synthesis inversion of atmospheric $\mathrm{CO}_{2}$ using the GISS tracer transport model, Aust. Div Atmos. Res. Tech. Pap., CSIRO, 29, 1-44, 1993.

Enting, I.G., C.M Trudinger, and R.J. Francey, A synthesis inversion of the concentration of $\delta \mathrm{C}$ of atmospheric $\mathrm{CO}_{2}$, Tellus, Ser. B, 47, 3551,1995

Esser, G, H.F.H. Lieth, J.M.O. Scurlock, and R J. Olson, Worldwide estimates and bibliography of net primary productivity derived from pre-1982 publications ORNL, report, Oak Ridge Natl. Lab., Oak Ridge, Tenn., 1997.

Etcheto, $J, J$. Boutin, and L. Merlivat, Seasonal variation of the $\mathrm{CO}_{2}$ exchange cofficient over the global ocean using satellite wind speed measurements, Tellus, Ser. B, 43, 247-255, 1991.

European Centre for Medium-Range Weather Forecasts (ECMWF), The description of the ECMWF/WCRP LevelIII-A Global Atmospheric Data Archive, Reading, England, 1994.

Fan, S.-M, M. Gloor, J Mahlman, S. Pacala, J.L. Sarmiento, T. Takahashi, and P.P. Tans, A large terrestrial carbon sink in North America implied by atmospheric and oceanic carbon dioxide data and models, Science, 282, 442-446, 1998.
Farquhar, G.D, J.R. Ehleringer, and K.T. Hubıck, Carbon isotope discrimination and photosynthesis, Annu. Rev. Plant Physiol., 40, 503537,1989

Follows, M.J., R.G. Williams, and J.C. Marshall, The solubility pump of carbon in the subtropical gyre of the north Atlantic, J Mar. Res, 54, 605-630, 1996.

Francey, R.J , P P. Tans, C.E. Allison, I.G. Entıng, J W.C. White, and M Trolier, Changes in oceanic and carbon uptake since 1982, Nature, 373, 326-330, 1995

Frıedlıngsteın, P., I. Fing, E. Holland, J. John, G. Brasseur, D. Erickson, and $\mathrm{D}$ Schumel, On the contribution of $\mathrm{CO}_{2}$ fertlization to the missing biospheric sink, Global Biogeochem. Cycles, 9, 541-556, 1995.

Fung, I., C.B. Field, C J. Tucker, and J. Gifford, $\mathrm{CO}_{2}$ release from land use modification in the tropics: An estimates of the sensivities, paper presented at Fifth International Carbon Dioxide Conference, Commonwealth Sci. and Ind. Res. Org., Caims, Australia, 1997.

Heımann, M., The global atmospheric tracer model TM2, report, Max Planck Inst. für Meteorol., Hamburg, Germany, 1995.

Heimann, $M$, and C.D. Keeling, $A$ three-dimensional model of atmospheric $\mathrm{CO}_{2}$ transport based on observed winds, 2, Model description and simulated tracer experiments, in Aspects of Climate Vartability in the Pacific and the Western Americas, Geophysical Monogr Ser, vol 55, edited by D.H. Peterson, pp. 237-275, AGU, Washington, D C., 1989.

Heımann, $M$, and $\mathbf{P}$. Monfray, Spatial and temporal variation of the gas exchange coefficient for $\mathrm{CO}_{2}, 1$, Data analysis and global validation, Report 31, Max Planck Inst. für Meteorol., Hamburg, Germany, 1989.

Hermann, M., C D. Keeling, and C.J. Tucker, A three-dimensional model of atmospheric $\mathrm{CO}_{2}$ transport based on observed winds, 3, Seasonal cycle and synoptic time scale variations, in Aspects of Climate Vartability in the Pacific and the Western Americas, Geophysical Monogr. Ser, vol. 55, edited by D.H. Peterson, pp. 277-303, AGU, Washington, D.C, 1989.

Heın, R., P.J Crutzen, and M. Heimann, An inverse modeling approach to investigate the global atmospheric methane cycle, Global Biogeochem Cycles, I/(1), 43-76, 1997.

Houghton, R.A., Emissions of Carbon from land-use change, Cambridge Univ. Press, New York, 1997.

Intergovernmental Panel on Climate Change (IPCC), Climate Change 1995 The Science of Climate Change, Cambridge Univ. Press, New York, 1995.

Kaminski, T., M. Heimann, and R. Giering, A global scale inversion of the transport of $\mathrm{CO}_{2}$ based on a matrix representation of an atmospheric transport model derived by its adjoint, paper presented at Fifth International Carbon Dioxide Conference, Commonwealth Sci. and Ind. Res. Org., Cairns, Australia, 1997.

Keelıng, C.D., R.B. Bacastow, A.F. Carter, S.C. Piper, T.P. Whorf, M. Heimann, W.G. Mook, and H.A. Roeloffzen, A three-dimensional model of atmospheric $\mathrm{CO}_{2}$ transport based on observed winds, 1 , Analysis of observational data, in Aspects of Climate Variability in the Pacific and Western Americas, Geophysical Monogr. Ser., vol. 55, edited by D.H. Peterson, pp. 165-236, AGU, Washington, D.C., 1989.

Keeling, C.D., J.F S. Chin, and T.P. Whorf, Increased activity of northern vegetation inferred from atmospheric $\mathrm{CO}_{2}$ measurements, Nature, 382, 146-149, 1996a.

Keeling, R.F., S.C. Piper, and M. Heimann, Global and hemispheric $\mathrm{CO}_{2}$ sinks deduced from changes in atmosphenc $\mathrm{O} 2$ concentration, Nature, $381,218-221,1996 \mathrm{~b}$.

Law, R.M., et al., Variations in modeled atmospheric transport of carbon dioxide and the consequences for $\mathrm{CO}_{2}$ inversions, Global Biogeochem. Cycles, 10, 783-796, 1996.

Lefevre, $\mathrm{N}$., A first step toward a reference $\mathrm{DPCO}_{2}$ map for the North Atlantic Ocean, Int. Geosphere-Biosphere Programme, Data and Inf Syst., Lab. d'Océanogr. Dyn. et de Climatol., Univ. P1erre et Marie Curie, Paris, 1995

Liss, P.S., and L. Merlivat, Air-sea gas exchange rates: Introduction and synthesis, in The Role of Air-Sea Exchange in Geochemical Cycling, edited by P. Buat-Menard, pp. 113-127, D. Reidel, Norwell, Mass., 1986.

Louis, J.F., A parametric model of vertical eddy fluxes in the atmosphere, Boundary Layer Meteorol., 17, 187-202, 1979.

Mahowald, N.M., P.J. Rasch, and R.G. Prinn, Cumulus parametrizations in chemical transport models, $J$. Geophys. Res., 100, 26,173-26,189, 1995.

Marland, G., T.A. Boden, A. Brenkert, R.J. Andres, and J. Olivier, $\mathrm{CO}_{2}$ from fossil fuel buming: Updates on the magnitude, distribution, and 
uncertainty of emissions estimates, paper presented at Fifth International Carbon Dioxide Conference, Commonwealth Sci. and Ind. Res. Org., Cairns, Australıa, 1997.

Masarie, K.A., and P.P. Tans, Extension and integration of atmospheric carbon dioxide data into a globally consistent measurement record, $J$. Geophys. Res, I00(D6), 11,593-11,610, 1995.

Metzl, N., A. Poisson, F. Louanchi, C. Brunet, B. Schauer, and B. Bres, Spatio-temporal distributions of air-sea fluxes of $\mathrm{CO}_{2}$ in the Indian and Antarctic Oceans: A first step, Tellus, Ser B, 47, 56-59, 1995.

Monfray, P., M. Ramonet, and D. Beardsmore, Longıtudinal and vertıcal $\mathrm{CO}_{2}$ gradients over the subtropical/subantarctic oceanic sınk, Tellus, Ser. $B, 48,445-456,1996$

Oeschger, H., U. Siegenthaler, U Schotterer, and A. Gugelmann, A box diffusion model to study the carbon dioxide exchange in nature, Tellus, 27, 168-191, 1975

Orr, J. C., The Ocean Carbon-Cycle Intercomparison Project of IGBP/GAIM, in Ocean Storage of Carbon Dioxıde, ed. W. Ormerod, IEA Greenhouse R\&D Programme, Workshop 3 -- Internatıonal Links and Concerns, pp. 33-52, ISBN 189837304 3, CRE Group Ltd., Cheltenham UK, 1996

Pak, B.C., R.J. Francey, I. Simmonds, and L.P. Steele, Using vertical profiles of $\mathrm{CO}_{2}$ concentration above Cape Grim to constrain the global carbon budget: The influence of tropical sources, paper presented at Fifth Intemational Carbon Dioxide Conference, Commonwealth Sci and Ind. Res. Org., Caıms, Australia, 1997.

Pearman, G I., and D.J. Beardsmore, Atmospheric carbon dioxıde measurements in the Australian region: Ten years of aircraft data, Tellus, Ser. B, 36, 1-24, 1984.

Press, W.H., B.P Flannery, S.A. Teukolsky, and W.T. Vetterling, Numerical Reciptes, Cambridge Unıv. Press, New York, 1987.

Raich, J.W., and W.H. Schlesinger, The global carbon dioxide flux in soil respiration and its relationship to vegetation and climate, Tellus, Ser. $B, 44,81-89,1992$.

Ramonet, M., Modélısation du transport atmospherique du dioxyde de carbone dans l'hémisphère sud, Ph.D. thesis, Univ. Paris VII, Paris, 1994

Ramonet, $\mathrm{M}$, and $\mathrm{P}$. Monfray, $\mathrm{CO}_{2}$ baseline concept in 3-D atmospheric transport models, Tellus, Ser. B, 48, 502-520, 1996.

Rayner, P., I. Enting, R. Francey, and R. Langenfelds, The recent time history of regional carbon sources as deduced from carbon dioxide and oxygen concentration and isotopic composition measurements, paper presented at $F_{1}$ fth International Carbon Dioxide Conference, Commonwealth Sc1 and Ind. Res. Org, Caims, Australia, 1997.

Rotty, R.M , Estımates of seasonal variations in fossil fuel $\mathrm{CO}_{2}$ emissions, Tellus, Ser B, 39, 184-202, 1987

Russel, G L, and J A. Lemer, A new finte-differencing scheme for the tracer transport equation, $J$. Appl. Meteorol, 20, 1483-1498, 1981.

Sellers, P J , Y. Mintz, Y.C. Sud, and A. Dalcher, A simple biosphere model $(\mathrm{SiB})$ for use within general circulation models, $J$ Atmos. Sci., 43(6), 505-531, 1986

Sellers, P.J., D.R. Randall, J.A. Collatz, J.A. Berry, C.B Field, D.A. Dazlich, $C$ Zhang, and L. Bounoua, A revised land-surface parameterization (SiB2) for atmospheric GCMs, 1, Model formulation, $J$ Clim., 9, 676-705, 1996a.

Sellers, P J., S.O. Los, J. Tucker, C.O. Justice, D.A. Dazlich, J.A. Collatz, and D.R. Randall, A revised land-surface parameterization (SiB2) for atmospheric GCMs, 2, The generation of global fields of terrestrial biophysical parameters from satellite data, J. Clim., 9, 706-737, 1996b.

Skole, D., and C. Tucker, Tropical deforestation and habitat fragmentation in the Amazon: Satellite data from 1978 to 1988 , Science, 260, 1905-1910, 1993.

Sullivan, C.W., K.R. Arrigo, C.R. McClain, J.C. Comiso, and J. Firestone, Distributions of Phytoplankton blooms in the southern ocean, Sctence, 262, 1832-1837, 1993.

Takahashı, T., J. Olafson, J.G. Goddard, D W. Chipman, and S.C. Sutherland, Seasonal variation of $\mathrm{CO}_{2}$ and nutrients in the high latitude surface oceans: A comparative study, Global Biogeochem. Cycles, 7(4), 843-878, 1993.

Takahashi, T., R.A. Feely, R. Weiss, R.H. Wanninkhof, D.W. Chipman, S.C. Sutherland, and T.T. Takahashi, Global air-sea flux of $\mathrm{CO}_{2}$ : An estimate based on measurements of sea-air $\mathrm{pCO}_{2}$ difference, Proc. Natl Acad. Sci, U.S.A., 94, 8292-8299, 1997.

Tanaka, M., T. Nakasawa, and S. Aoki, Time and space variations of tropospheric carbon dioxide over Japan, Tellus, Ser. B, 39, 3-12, 1987.

Tans, P.P., I.Y Fung, and T. Takahashi, Observational constraints on the global atmospheric $\mathrm{CO}_{2}$ budget, Science, 247, 1431-1438, 1990.

Tans, P.P , I Y. Fung, and I.G Enting, Storage versus flux budgets: The terrestrial uptake of $\mathrm{CO}_{2}$ during the 1980s, in Biotic Feedbacks in the Gobal System, edited by G.M. Woodwell and F.T. Mackensie, pp. 351-366, Oxford Univ Press, New York, 1995

Tarantola, A., Inverse Problem Theory, Elsevier, New York, 1987.

Tarantola, A., and B. Vallette, Generalized nonlinear inverse problems solved using the least squares criterion, Rev Geophys., 20(2), 219 232, 1982.

Thoning, K.W., P.P. Tans, and W.D. Komhyr, Atmosphenc carbon dioxide at Mauna Loa Observatory, 2, Analysis of the NOAA GMCC data, 1974, 1985, J Geophys. Res., 94(D6), 8549-8565, 1989.

Tiedtke, M , A comprehensıve flux scheme for cumulus parametrization in large-scale models, Mon. Weather Rev., /17, 1779-1800, 1989.

Watson, A.J., C. Robinson, J.E. Robınson, P.J. Williams, and M.J. Fasham, Spatıal variability in the sink for atmospherıc carbon dioxide in the North Atlantic, Nature, 350, 50-53, 1991

Wong, C.S , Y.H Chan, J.S. Page, G.E. Smith, and B. R D., Changes in equatorial $\mathrm{CO}_{2}$ flux and new production estimated from $\mathrm{CO}_{2}$ and nutrients levels in Pacific surface waters during 1986/87 El Nino, Tellus, 45, 64-79, 1993.

P. Bousquet, P Ciais, P. Monfray, P. Peylın, and M. Ramonet, UMR CNRS/CEA, CEA de Saclay, Orme des Merisiers, Bat. 709/LSCE, Gif sur Yvette cedex, F-91191, France. (bousquet@lsce.saclay.cea.fr)

(Received November 2, 1998; revised May 14, 1999; accepted May 19, 1999.) 